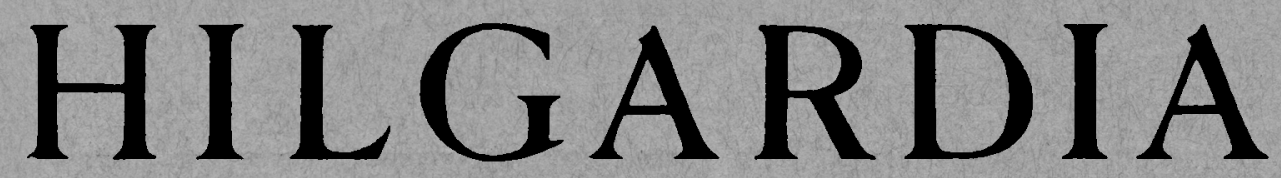

A Journal of Agricultural Science Publisbed by the California Agricultural Experiment Station

\title{
STATISTICAL ANALYSIS OF SUPPLY RESPONSE IN LATE SPRING POTATOES IN CALIFORNIA
}

CHESTER O. MCCORKLE, JR., and YAIR MUNDLAK 
This study attempts to specify an acreage response function for late spring potatoes in California and to estimate the parameters of alternative expressions of this function. Least-square estimates of these parameters indicate that gross income from competing crops, potato prices from previous season(s), and acreage available for potatoes determine in large part the variation of potato acreage with trend removed.

Two possible policy applications are suggested: the calculation of year-to-year acreage forecasts and the achievement of acreage goals through the manipulation of prices of potatoes and alternative crops, as suggested in various agricultural programs turning on forward pricing. 


\title{
H $\quad$ I A Journal of Agricultural Science Published by the California Agricultural Experiment Station
}

\section{STATISTICAL ANALYSIS OF SUPPLY RESPONSE IN LATE SPRING POTATOES IN CALIFORNIA}

\author{
CHESTER O. MCCORKLE, JR., ${ }^{2}$ and YAIR MUNDLAK ${ }^{3}$
}

\section{INTRODUCTION}

Estimating AGGREGate aCREAGE ADJUSTMENTS to various economic and institutional stimuli within given production areas is a major problem confronting researchers in the field of production economics. With marketing quota and acreage allotment provisions playing an important role in present-day agricultural programs, increasing interest will be devoted to aggregate acreage adjustments for crops affected directly and indirectly by these institutional forces in an attempt to evaluate the net impact of these programs. For example, the reappearance of cotton acreage allotments has aroused interest in estimating the use of diverted cotton acreage as a basis for judging the net impact on the earnings of the farms affected directly by allotments and on the agricultural economy in general. In order to provide accurate estimates of the potential role of specific alternatives, it is necessary to know the factors that influence the acreage and production of the alternatives under consideration. Relative magnitudes of these influences and, more important, estimates of absolute magnitudes are essential.

This study attempts to specify the major determinants of late spring potato acreage in California-an important alternative for cotton on much of the diverted acreage in the southern San Joaquin Valley. Specifically, an attempt is made to approximate a supply response function for late spring potato acreage in California and to estimate the parameters of alternative formulations of this functional relationship. It is necessary to indicate immediately that the term "supply response" as used in this study differs from the strict usage of the term in economic theory. The conventional supply function commonly depicts quantities per unit of time offered at alternative prices in an instantaneous sense. The concept of "supply response" has been introduced to represent the impact of price on subsequent supplies offered. In early studies of supply response in agriculture, the concept was further narrowed to refer to the relationship between price

\footnotetext{
${ }^{1}$ Received for publication A pril 25, 1955.

${ }^{2}$ Assistant Professor of Agricultural Economics and Assistant Agricultural Economist in the Experiment Station and on the Giannini Foundation, Davis.

${ }^{3}$ Research Assistant, Department of Agricultural Economics, Berkeley.
} 
of a given commodity in one production period and production of that commodity in the subsequent period. In this study the term has a somewhat broader meaning. It is used to express the average relationship between acreage of late spring potatoes over the given period studied and specified variables (including prices or gross returns as defined in each specific formulation) which are considered in the general model as relevant in determining the acreage. In interpreting these results it is implicitly assumed that so long as the basic theoretical model continues to depict the acreage structure accurately, the substitution of appropriate values for the independent variables will continue to provide estimates of late spring potato acreage in California to which probability limits ean be assigned and which possess some desired statistical properties discussed below.

A brief description of the late spring potato industry in California will assist in focusing attention on the problem of supply response and those important factors which bear on changes in acreage from year to year. Since estimates have been available, late spring potato acreage in California has expanded from 10,000 in 1929 to a record high of 84,000 acres in 1953. California's late spring potato crop is planted in late January and February and is harvested from late April through early July depending on planting date and on the particular district. Two-thirds to three-quarters of the state acreage is found in Kern County each year. Tulare, Kings, and Kern counties in the southern San Joaquin Valley are the major producing counties, but a relatively small acreage is planted each year in the Chino district east of Los Angeles.

Late spring potatoes are produced on farms specializing in irrigated spring and summer field crops. On farms in the three major early spring potato counties in California, cotton and alfalfa have been the other major enterprises, though acreages of small grains, beans, grapes and tree fruits, sugar beets, seed crops, or other vegetable crops are included in the organizations of some of the farms. Field corn has become an important alternative enterprise in this area very recently. The fact that late spring potatoes are only one of several enterprises on the farms where produced and that other profitable alternatives have been available has led in recent years to fluctuating total late spring potato acreage from year to year depending on the price outlook for potatoes and alternatives.

Expansion in acreage and production of potatoes in other states where growing conditions favor the production of early maturing crops has tended to reduce the early season price advantage enjoyed by Kern County producers in the past. In some seasons stored stocks of previous season late potatoes have also tended to reduce early season prices. While it is not possible to predict accurately the impact of this interregional competition, there is no indication that the partial loss of the early market will be regained.

A brief examination of procedure and a qualitative statement of findings at this point should assist the reader in evaluating and interpreting the substance of this paper. In this study supply response was separated into its two components-acreage and yield. The hypothesis that potato yields do not reflect year-to-year variations in prices was tested with available evidence and was not rejected. The hypothesis was accepted that yield changes reflect primarily changes in the level of technology. Thus, it was 
assumed that potato farmers adjust output to the economic environment through acreage adjustment. This line of argument, with appropriate modification, can be extended to other agricultural enterprises, particularly crop production activities.

It is suggested in this study that late spring potato acreage in California is affected by the total acreage available for summer irrigated field crops in the locality where the bulk of the crop is produced and by the expected relative profitability of late spring potatoes compared with other alternatives. Specific measurements for these variables are not available in the most appropriate form, necessitating their approximation from available data.

Least-squares estimates were obtained for the parameters in the supply (acreage) response equation. These estimates are consistent and relatively efficient. Both the yield and acreage equations were formulated within the general framework of an econometric model portraying the structural relationships in the industry. Both were functions of predetermined variables only (either exogenous or lagged endogenous). Therefore, the least-squares estimates of the parameters in these equations were both consistent and relatively efficient.

The empirical results of this analysis indicate that the late spring potato acreage in California is positively associated with both lagged potato and alfalfa prices (and returns) and with total land available for annual crops and alfalfa. The late spring potato acreage of the state varies inversely with lagged cotton prices (and returns). Trend variables were introduced to carry technological change and other minor variables in some of the formulations. The effect of trend increases at a decreasing rate over the relevant time span of the study. Elasticities of potato acreage with respect to individual alternatives indicate that acreage response is inelastic with respect to any single independent variable.

This study suggests several possible policy applications which could be developed from similar and more detailed analyses. First, the possibilities of acreage prediction from year to year based on this analysis are discussed and demonstrated. The confidence limits associated with such a prediction, together with the assumptions regarding structural change in the basic model, delimit the scope of this type of application. A second application of this type of analysis is suggested whereby acreage goals might be achieved through manipulation of relative prices of the enterprise under consideration and each of the alternative enterprises.

A further amplification of the supply (acreage) response concept as used in this study is desirable in the interest of avoiding misinterpretation. By segregating the supply function into its two components-yield and acreage-and viewing acreage as the direct result of producers' reaction to specified stimuli (including price and yield expectations), it is then plausible to view the acreages in any given year as the aggregate result of the planning of individual late spring potato producers. It therefore follows that through proper selection of variables to represent these economic and institutional stimuli to which these producers responded, a functional relationship can be constructed, which approximates the way early potato producers respond in a world of uncertainties where planning is based largely on expectations. It is this type of functional relationship that is formulated in this study. 
Alternative forms have been developed, each involving the least-squares method of estimating the parameters.

In the process of selecting variables and formulating the alternative forms, benefit was derived from previous research. The works of Bean, Hartkemeier, Cox and Quintus, Elliot and Wells, Moore, Ezekiel, Mighell and Allen, Black, and Henry Schultz must be singled out for specific mention." Since 1940 little has been added to the literature on the application of statistical concepts and techniques to the general type of problem undertaken in this study. It is the purpose of this study to apply statistical analysis involving available techniques to a specific problem in acreage response-acreage response in California late spring potatoes. Earlier research has made it possible to construct a sound theoretical model of late spring potato acreage response in California. Extensive supplementary information on types of farming, farm resources, input-output relationships, and determinants of farm organization is available as a result of previous research on California cotton-potato farms (McCorkle, 1953; McCorkle and Hedges, 1952).

\section{ALTERNATIVE APPROACHES TO SUPPLY (ACREAGE) RESPONSE ANALYSIS}

Before detailed explanation of the model and variables is undertaken, a brief consideration of alternative approaches to the problem of estimating supply response might assist in evaluating the techniques of this study. One approach would utilize some of the tools of production economicsbudgeting or, more formally, activity analysis - to determine the expected individual firm response. Where sufficient homogeneity prevails among farms in the area or where percentages of the aggregate acreage composed of farms with specified characteristics are known, this approach would be fruitful with one major exception. This type of analysis would tell the researcher what should be done for individual firm profit maximization, not

\footnotetext{
${ }^{4}$ Bean (1929) directed his attention to the relationships between prices received by producers and subsequent output changes for nine agricultural products. Graphic correlation method was employed to relate previous season prices to harvested acreage, with residuals plotted against prices for two seasons previous. The conclusions were qualitative but evidence of implicit estimates of supply response elasticities exists.

Hartkemeier (1932) considered the effect of weather as well as price in his study of factors affecting the production of corn and potatoes. The importance of comparing net income per acre for all alternative crops when considering the production response of any particular crop was emphasized by Cox and Quintus (1932) in a study of supply response in Minnesota. Elliot and Wells (1932) considered net incomes per acre among alternatives in a graphical correlation analysis of flax acreage response. These authors attempted to correlate the percentage change in flax acreage to the ratio of net income of wheat per acre to that of flax. Moore (1925) introduced price ratios of the preceding year in his study of demand and supply of potatoes in the United States. Ezekiel (1928) further emphasized the importance of lagged prices in statistical studies of supply response. He carefully pointed out the legitimate interpretation of the results of this type of analysis, indicating that the relations discovered represent those existing in a specified period in the past. This type of analysis does not indicate how long the same relationships will hold or what new factors may arise which will change the relations. Mighell and Allen (1940) compared statistical methods for approximating long-term supply schedules with other methods such as synthetic budget analysis as suggested by Black (1932) earlier. The pioneering work of Henry Schultz (1938) in the statistical analysis of supply and demand cannot be overlooked in a study of this type.
} 
what is done within the context of diverse entrepreneurial goals and expectations. This approach may assume alternative sets of input-output ratios, price and cost expectations, and values for the other parameters. However, individual operators may have unique expectations for these parameters quite different from the range considered. At best it provides an indication of how "rational" farmers should behave in a system of alternative static positions, each position being carefully prescribed.

In contrast to this normative type of approach, the problem of supply or acreage response can be treated directly by formulating a statistical model indicating factors associated with acreage and production changes. At least two types of data can be used in this second approach. One possibility is to draw on data from a cross-sectional sample of farms. These data would consist of observations on organizational adjustments made by individual farm operators over a period of several years. This approach could include additional variables which would be difficult to inject in an aggregative model. Time series analysis of available data presents another possibility. The estimates of parameters in the model from analysis of data taken from a stratified random sample of farms, or other appropriate sample design, could be expected to provide a more adequate predictive device (at least in the short run). These estimates would be based on a larger sample, resulting in narrower confidence intervals than would be obtained from a time series analysis where the availability of "good" data is limited both physically and by the need for continuous caution against inclusion of periods involving material structural changes.

From a practical point of view, the choice between the two methods just compared is strongly affected by the cost of procuring data. Cross-sectional sampling a large number of farms, however desirable it may be, is comparatively expensive in terms of both time and money. Largely for this reason, statistical analysis of time series data has been employed in this type of study.

\section{THE SUPPLY FUNCTION}

The formulation and estimation of the parameters of the supply equation for late spring potatoes in California is the principal concern of this study. ${ }^{5}$ This supply function can be viewed as being composed of two segmentsacreage and yield-since for this semi-perishable commodity the supply for any season is equal to the acreage times the average yield per acre. While acreage harvested for commercial sales would be the most appropriate measurement of acreage in developing a supply function, for purposes of this study estimates of planted acreage are used. This selection is made in order to separate out the "planned" portion of the total supply. The decisions made by producers regarding planted acreage must be completed by the end of the planting period. Furthermore, each individual producer has full control over the total acreage he wishes to plant.

However, variations in yield from season to season arise from both natural causes and changes in production practices. Decisions regarding yield-influencing production practices are made both before and during the

\footnotetext{
${ }^{5}$ The place of the supply equation in the more general framework of economic relationships in the late spring potato industry is presented in Appendix D.
} 
growing season. It is desirable to determine the relative importance of these two supply-influencing factors in order to select appropriate variables in developing a function for estimating purposes. This necessitates separate treatment for each of these two elements determining total supply. This procedure also facilitates testing the hypothesis that yield response to shortrun changes in economic variables is not important in altering total supply.

An attempt has been made to derive empirical evidence on which to base acceptance or rejection of this hypothesis. Preliminary investigation of yield and acreage variables as possible dependent variables indicates that further analysis can best be undertaken with acreage as the dependent variable.

The yield relationship can be expressed as follows:

$$
Y=f\left(G, L, P_{\epsilon}\right)+u,
$$

where yield $(Y)$ is depicted as a function of the general level of potato yields $(G)$, expected price $\left(P_{\epsilon}\right)$, and the position on the particular production function $(L)$ selected by specific producers, which in itself is partially determined by expected price. The disturbance term $(u)$ is a random variable injected to account for the difference between observed and expected values of $Y$. The general level of potato yields is selected to represent the adopted level of technology. This reflects the level of knowledge about practices as modified by the degree of implementation of these practices.

No acceptable measure of the level of intensity of production is available for year-to-year comparisons, nor is such a measure available for any given year. Without this variable, the functional relationship reduces to:

$$
Y=f\left(G, P_{\epsilon}\right)+v .
$$

The farm price for late spring potatoes received by California producers lagged one year was used to estimate the expected price $\left(P_{\epsilon}\right)$. A moving average yield for the previous five years was selected as the variable to approximate the general level of yields $\left(Y_{5}\right)$. The following regression equation was derived: ${ }^{\circ}$

$$
Y_{t}=0.625+0.892 Y_{5}-0.035 P_{t-1} \quad R^{2}=0.84
$$

The regression coefficient for the price variable is not significantly different from zero at any acceptable level of significance. The regression coefficient for the five-year average-yield level suggests a close association, on the average over the period examined, between the average-yield variable and yield in a given year $(t)$. A unit change in the previous five-year average was associated on the average with a change of 0.89 units in the same direction in the dependent variable. This analysis suggests that the yield of late spring potatoes can be viewed primarily as a function of level of technology.

The effect of omitting the variable representing the level of intensity of

' Figures in parentheses are $t$-ratios used in testing significance of the regression coefficients. 
production warrants consideration. The level of intensity of production for any season can be considered a function of the production function employed, the price of the product, and the price of the factors. It can be argued that the production function is reflected directly in the level of technology and was therefore implicitly introduced. The price of the product was included explicitly in the yield equation. Therefore, the only component neglected was the factor price component. It is possible that some degree of short-run sensitivity of yield to factor price variation prevails. However, it is believed that planned response to factor prices within the production period is not as important as acreage in determining total supply.

A further note on the nature of the yield and acreage equations in the general model (Appendix D) is required. Both the yield and acreage equations contain only one variable which is neither a pure exogenous nor a lagged endogenous variable. Thus, the parameters of these equations can be estimated by the method of least squares, the estimates being the same as the maximum likelihood estimates under these conditions. These estimates are, therefore, consistent and relatively efficient. ${ }^{7}$ Subsequent analysis involves only the acreage equation.

\section{THE VARIABLES}

It has been suggested that late spring potato acreage is determined by the expected relative profitability of potatoes with respect to alternatives and by total cultivated acreage in the potato-producing areas. A discussion of the variables included in the various empirical counterparts of the general supply-response function will indicate why particular variables have been selected for inclusion in the empirical equations.

Since expected net returns are not known, these must be approximated. Making the reasonable assumption that producers base their expectations on past experience, it is possible to resort to past values of the relevant variables as approximations to the expected values. ${ }^{8}$ The introduction of lagged variables logically follows. This is not to say a priori what time lag should be used for any specific variable. The question of time lag would involve asking the producer how many years of past experience he considers in formulating his expectations and how he weights the past values relative to one another. In this analysis two types of lagged variables have been used. Values for competing crops and potatoes have been lagged one year in some formulations, and an average of two years (each year equally weighted) has been used in other formulations.

The question of what values to use in comparing alternative enterprises with potatoes presents difficulty. Experience indicates that what farmers compare in two or more enterprises is the relative net incomes per acre.

\footnotetext{
${ }^{7}$ For a discussion of the problems of estimating economic relationships in the simultaneous-equations setting, several excellent sources are available. Girshick and Haavelmo's (1947) study of the demand for food presents an application of the simultaneous-equations approach to a specific problem. The work of Koopmans and Hood (1953) on estimating simultaneous linear economic relationships is recommended. A textbook presentation is available in Klein's (1953) A Textbook of Econometrics.

${ }^{8}$ For a discussion of relationships between past values and price expectations in supplyresponse behavior, reference is made to the work of Mordecai Ezekiel on the "Cobweb Theorem" (1938).
} 
This comparison, for practical application in this type of analysis, would require historic cost-of-production data as well às yield and farm price information for a relatively long period. Unfortunately, these data are not available in any reliable form over the period studied. It is possible that an indexed series of costs could be constructed, but this did not appear feasible in this study. Furthermore, if supply response studies are going to require this type of detail, the possibility for expanded statistical research in supply response appears more remote.

Two alternatives are suggested. One possibility is to compare gross returns per acre (yield $\times$ price). A second possibility is to consider relative prices alone, assuming that producers do not anticipate at the planning stage any significant fluctuations in yields from year to year. In an irrigated area not subject to severe climatic shifts, wide variation in insect incidence, or other production hazards from year to year, it is logical to assume this type of behavior. ${ }^{9}$ In either case it is implicitly assumed that the relative costs among alternatives remain constant through time. This assumption cannot be accepted comfortably.

One method for avoiding this type of problem for statistical purposes is to introduce a trend variable which will (among other things) inject the net effects of cost changes. Conceptually, a time variable introduces the net effect of several variables the individual impact of which is too small to warrant its inclusion as a separate independent variable. Thus, the trend variable will reflect not only cost changes over time but would be expected to reflect other related changes, measures of which are not included and variables for which are not introduced. The inclusion of the trend variable also injects into the formulation the trend in late spring potato yields relative to yields of other crops.

Since the rate of change of the dependent variable through time is not considered to be constant, a time variable to the second power is introduced to permit variation in the rate of change. An alternative approach to the problem of supply response, which would eliminate the imposition of linearity constraints, could be formulated in terms of year-to-year changes. Taking acreage as the measure of supply response for late spring potatoes, this approach would employ changes in acreage from one year to the next as the dependent variable. The values of the independent variables would likewise be expressed as first differences. ${ }^{10}$

The final variable employed in this analysis is total acreage in annual crops and alfalfa in Kern County. While this total acreage does not represent potential potato land because of the type of soil required for satisfactory late spring potato yields, any expansion in total acreage under cultivation presents an opportunity for shifts by other crops more tolerant to the poorer soils in the outlying areas. The alternative enterprises to potatoes employed in this study have been alfalfa and cotton. Because of the rapid rise in importance of field corn, it is probable that further work in this field should introduce this alternative explicitly. At the time of this study, field corn had not yet assumed an important role.

\footnotetext{
${ }^{\circ}$ This position is supported by findings of Schultz and Brownlee (1942) in their research in expectation models applicable to agriculture.

${ }^{10}$ The "first differences" approach is sometimes employed to remove serial correlation, assuming that there is perfect correlation between disturbance terms in successive points of time.
} 


\section{THE EMPIRICAL RESULTS}

Seven empirical formulations of the acreage (supply) response function from the structural model have been developed. The basic data employed in the empirical analyses consist of time series of prices received by California farmers, state average yields for the crops included, total acreage in annual crops and alfalfa in Kern County, and late spring potato acreage in Kern County (table 1). Not all of the variables entering each formulation are included in the table, but any variable used and not appearing in the table has been calculated from those included. For example, gross returns per acre for a given commodity is obtained by multiplying yield by average seasonal price. In all formulations time series data for the years 1929 to 1953 have been used, with 1950 excluded because of cotton acreage restrictions in that year.

First degree, second degree, and logarithmic functions have been fitted to the data. The various results obtained (table 2) will be discussed and compared. The analysis has been extended to suggest certain selected policy applications of the techniques involved.

The net regression coefficients represent net association of the dependent variable with each of the respective independent variables as averaged over the period studied, while the influence of the other independent variables is held constant. Obviously, none of the variables are actually held constant from year to year. Therefore, the change in the dependent variable (acreage) represents the net effect of the changes of the various independent variables, which may change in direction and magnitude from year to year. The constant term in each equation has little practical meaning. In a strict interpretation, the dependent variable takes on the value of the constant term when the value of all the independent variables is zero. Such a case is outside the range of observations.

The first equation derived expresses acreage of late spring potatoes in California as a linear function of gross returns per acre for potatoes, alfalfa, cotton, and total cultivated acreage in Kern County planted to annual crops and alfalfa. The value of the coefficient of multiple determination obtained, when adjusted for degrees of freedom, was 0.916 , indicating a good fit to the data. However, the value of the $t$-ratio for the late spring potato gross-return-per-acre regression coefficient was not of sufficient magnitude to lead to rejection of the null hypothesis that this coefficient actually has zero value.

Equation 2 was the first alternative considered. The principal difference between the first two equations is in the inclusion of the time variables in the latter. However, because of the high intercorrelation between late spring potato yields and the time variables, it appeared logical to remove the gross return for the late spring potato variable and substitute a price variable for late spring potatoes. The time variables reflect yield variation through time but do not carry the price component of the gross return variable. Therefore, the price component had to be introduced explicitly. These changes produced an equation with a high degree of fit $\left(\bar{R}^{2}=0.986\right)$ and improved the $t$-ratios for all of the independent variables except the aggregate cultivated acreage variable. The residuals from equation 2 were plotted against the net regressions to determine whether or not the fit might 


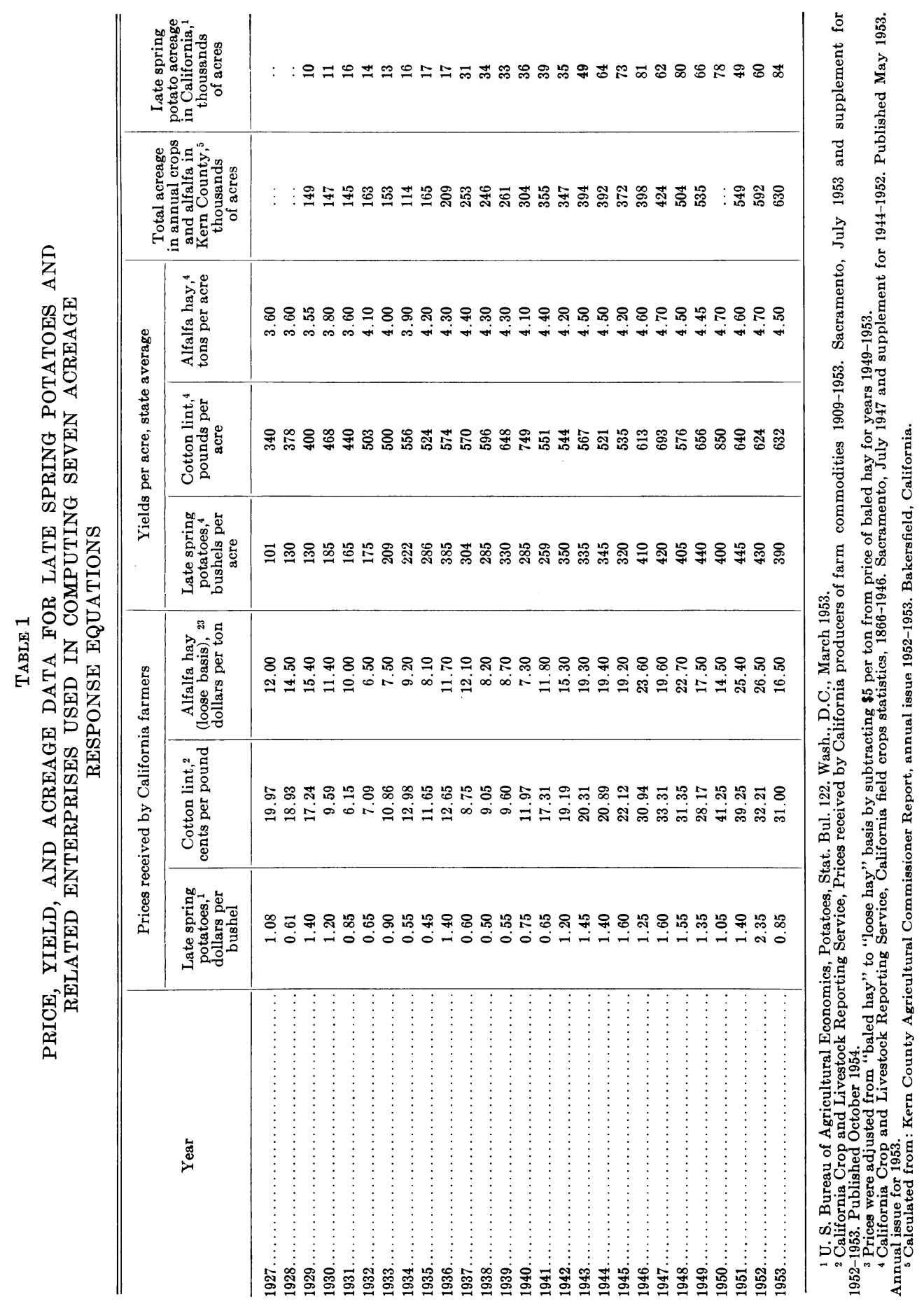




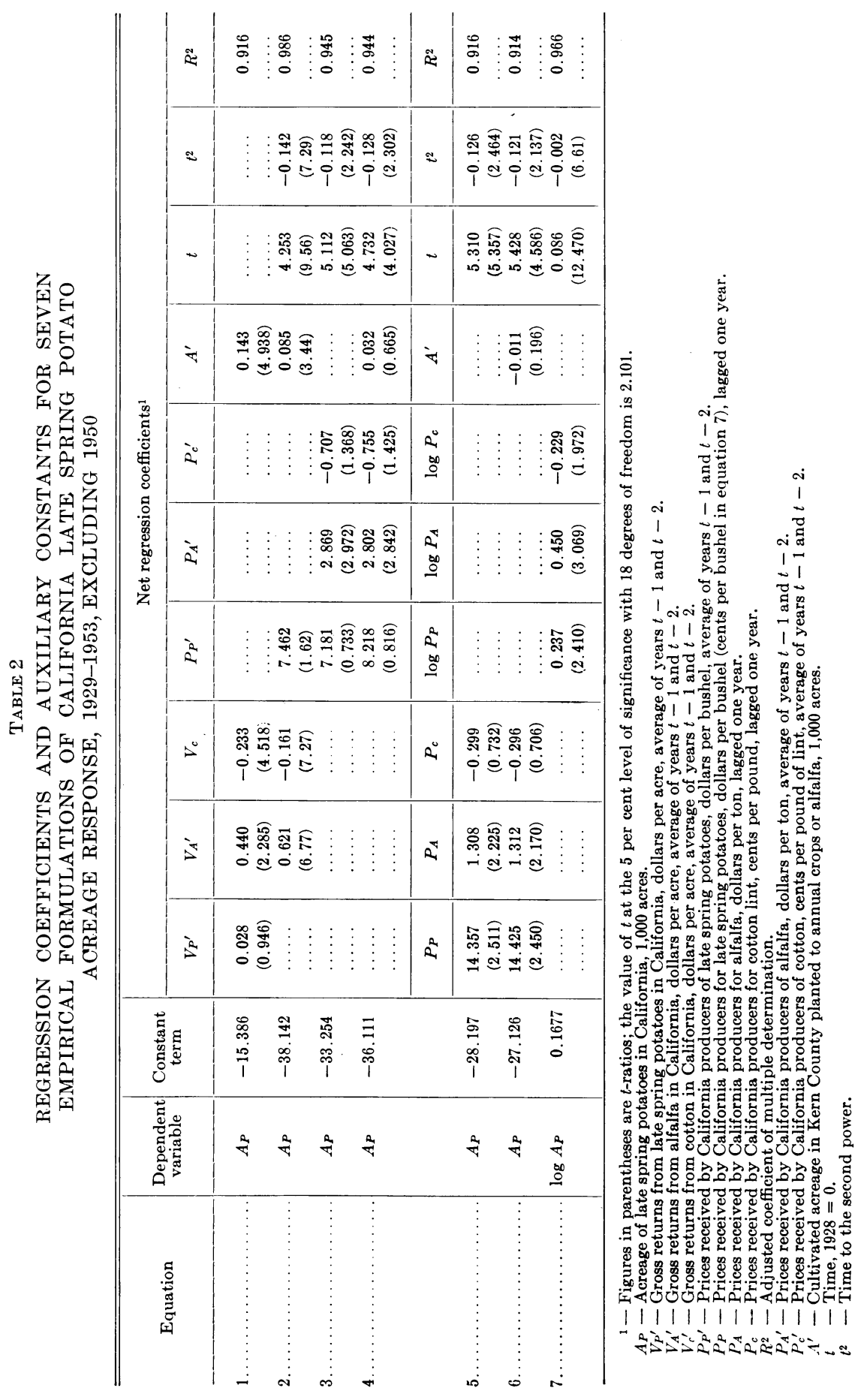


be improved by the introduction of higher powers of the independent variables (Appendix A). An examination of the residuals plotted on independent variables included in the equation indicates that the functional relationship is essentially correct and that nothing can be gained by introducing another type of function. The magnitude of the adjusted coefficient of determination suggests that there is little variation left to be explained by independent variables omitted from the equation. However, the final residuals were tested against appropriate barley prices and no association was found.

Equations 3 and 4 substitute two-year average lagged prices for gross returns as independent variables representing potatoes, cotton, and alfalfa. The time variables are the only others included in equation 3 , and while the fit is satisfactory $\left(\bar{R}^{2}=0.945\right)$, the $t$-ratios for the critical variables are of insufficient magnitude. Because of the significance of the total cultivated acreage variable in equations 1 and 2, it was introduced in equation 4 , but with negative results. The adjusted coefficient of multiple determination remained essentially unchanged and the $t$-ratios were not improved.

Coefficients for the price and gross return variables in the first four equations were simple arithmetic means of the first- and second-year lagged values,

$$
\frac{(t-1)+\frac{(t-2)}{2}}{.}
$$

In equations 5 and 6 , the coefficients are measured on the basis of price lagged one year. Equation 5 expresses California late spring potato acreage as a function of prices of late spring potatoes, alfalfa, and cotton lint, each lagged one year, and the time variables. Equation 6 contains the above variables and also the aggregate cultivated acreage variable. In neither formulation is the fit significantly superior to that of any of the equations previously discussed. It is to be noted that the $t$-ratios have undergone a shift in these two equations as compared with earlier versions. The potato price variable now is significant at the 5 per cent level, whereas the cotton price variable is not. It is also of interest that regardless of whether the independent variables for crops were expressed in terms of prices or gross returns, the adjusted coefficients of multiple determination were generally smaller where values were lagged one year than where two previous-year averages were used. This is not suggested as a general finding of this study. The question of how farm operators formulate their expectations requires extensive research before these expectations can be used as guides to how variables should be lagged in statistical treatment of problems of supply response in agriculture.

Recognition of the possibility of joint rather than additive influence of the independent variables on the late spring potato acreage in California suggested an equation such as equation 7 . An exponential function involving the variables in equation 5 produced a superior fit in that the adjusted coefficient of multiple determination increased from 0.919 to 0.966 . Furthermore, the $t$-ratios assumed values significant at the 5 per cent level with the exception of the net regression coefficient for the cotton price variable, which was significant at the 10 per cent level. 
After examining the behavior of the residuals as to their distribution about the net regression functions and the degree to which variations in the dependent variable have been accounted for by the various expressions, equations 2 and 7 were accepted for further development, explanation, and interpretation.

The coefficients in equation 2 have been interpreted as an example of the interpretation of the results obtained. The coefficient of gross returns per acre of cotton averaged for two previous seasons $\left(V_{c}^{\prime}\right)$ indicates that, with the effects of other independent variables remaining unchanged, an increase (decrease) of $\$ 10$ per acre in gross returns per acre for cotton was associated, on the average over the period studied, with a decrease (increase) of 1,610 acres in the following year in the acreage of late spring potatoes in California. The coefficient of farm price of late spring potatoes in California averaged for two previous seasons $\left(P_{P}{ }^{\prime}\right)$ indicates that, with effects of other independent variables remaining constant, an increase (decrease) of 10 cents per bushel in the average price received by farmers in the two previous seasons was associated, on the average over the period studied, with an increase (decrease) of 746 acres of late spring potatoes in the following year in California. The coefficient of gross returns per acre for alfalfa averaged for the two previous seasons $\left(V_{A}{ }^{\prime}\right)$ indicates that, with effects of other variables held constant, an increase (decrease) of $\$ 10$ per acre in gross returns per acre from alfalfa averaged for two previous years was associated on, the average over the period studied, with an increase (decrease) of 6,210 acres in acreage of late spring potatoes in California in the following year. The coefficient of total cultivated acreage in Kern County planted to annual crops and alfalfa $\left(A^{\prime}\right)$ indicates that an increase of one thousand acres in the total cultivated acreage in the county occupied by the specified crops was associated, on the average, with an increase of 85 acres in the late spring potato acreage in California.

The coefficients of time $\left(t\right.$ and $\left.t^{2}\right)$ indicate the net impact of a group of factors that were not individually important enough to introduce into the equation. With the effects of other variables remaining constant, a change of one unit of time (one year) was associated, on the average over the period studied, with a change of $t(4.253-0.142 t)$ thousand acres in the acreage of late spring potatoes in California. The value of $t$ is determined by the number of years elapsing between the year for which the estimate is being made and the origin $(1928=0)$. For example, the late spring potato acreage associated with the net effect of time in 1930 was:

$$
2[4.253-(0.142)(2)]=7,942 \text { acres }
$$

whereas in 1953 :

$$
25[4.253-(0.142)(25)]=18,200 \text { acres }
$$

In the first two years an acreage increase of 3,971 acres per year was associated with the variables represented by "time" and the "time squared." In 1953, the increase associated with these variables declined to 728 acres per year. The increase in acreage associated with time trend, therefore, has increased at a decreasing rate.

The algebraic signs of the coefficients should be examined to see whether or not they are logical in terms of known farm organization characteristics 
and determinants. In California increased returns from cotton per acre in the two previous production periods would be expected to result in a decrease in late spring potato acreage in the year following when most late spring potato producers also devote a substantial portion of their farms to cotton. A positive relationship between previous late spring potato prices and late spring potato acreage in the following year is a logical result. A positive relationship between the value of alfalfa per acre over the previous two-year period and late spring potato acreage the following year requires explanation. Alfalfa and cotton compete for a limited midsummer water

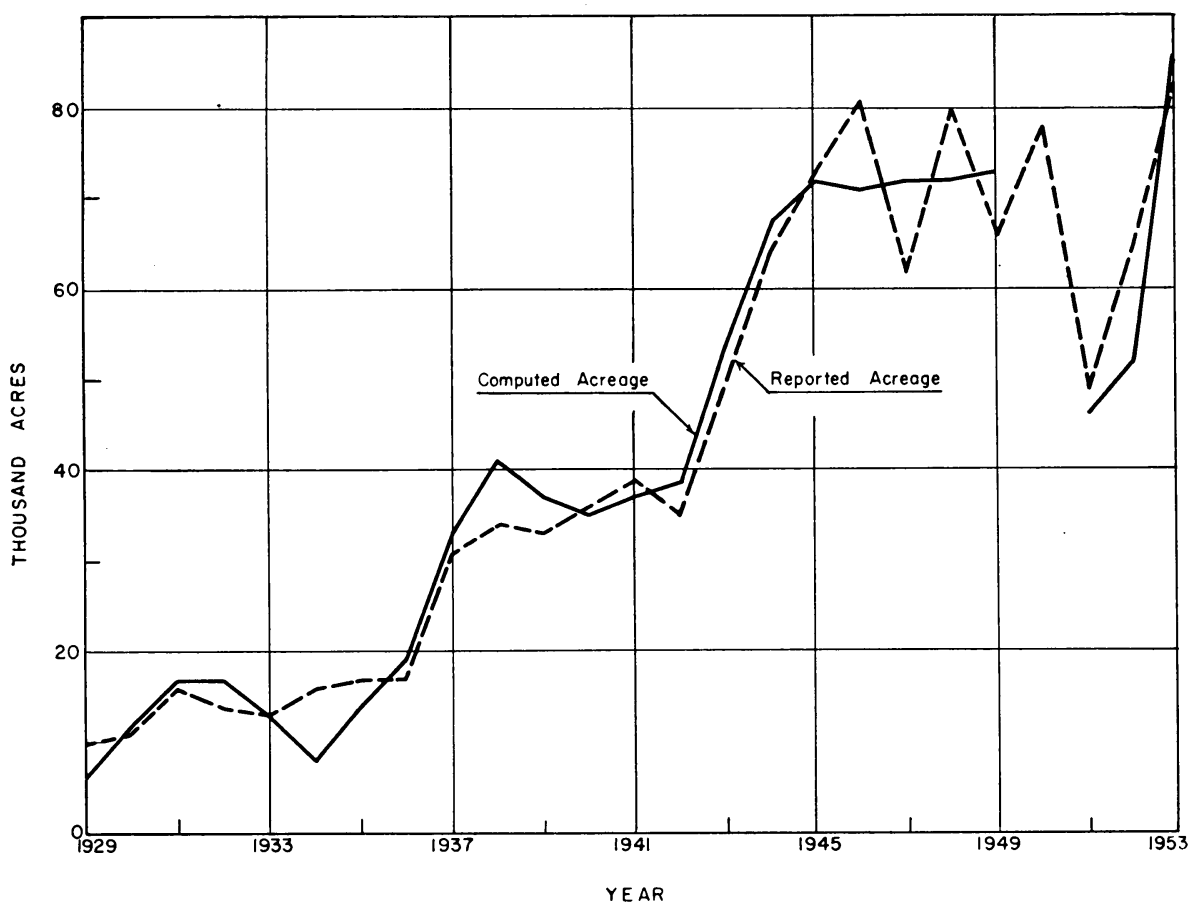

Fig. 1. Acreage of late spring potatoes in California, 1929-1953 (excluding 1950); a comparison of reported acreage with acreage estimates computed from the multiple regression equation (2).

$A_{P}=-38.142+7.462 P_{P^{\prime}}+0.621 V_{A^{\prime}}-0.161 V_{C^{\prime}}+0.085 A^{\prime}+4.253 t-0.142 t^{2}$

supply on most farms in the cotton-potato belt of California. Expansion of alfalfa on the typical farm in this area must take place at the expense of cotton but not in a one-to-one ratio with respect to the resource water, since alfalfa requires approximately twice as much water per acre as cotton. Therefore, expansion of alfalfa frees land that cannot go into other summer crops requiring water and is, therefore, available for winter and spring crops. Irrigation of late spring potatoes is completed before alfalfa requires heavy irrigation.

A positive association between late spring potato acreage and total acreage in annual crops and alfalfa is to be expected. Little if any land brought into production in recent years has been cropped to late spring potatoes largely because the potato plant is intolerant of any adverse soil charac- 
teristics, particularly salts. Therefore, the level of expansion in late spring potatoes as a result of new land being brought into irrigated production must result from displacement and substitution. This is particularly true of initial relationships between late spring potato acreage and newly irrigated acreage in the county. As newly developed areas are farmed, surface salt deposits may diminish, permitting the production of less saline-tolerant plants.

The positive relationship between time and late spring potato acreage and the negative relationship with the square of the time variable indicate

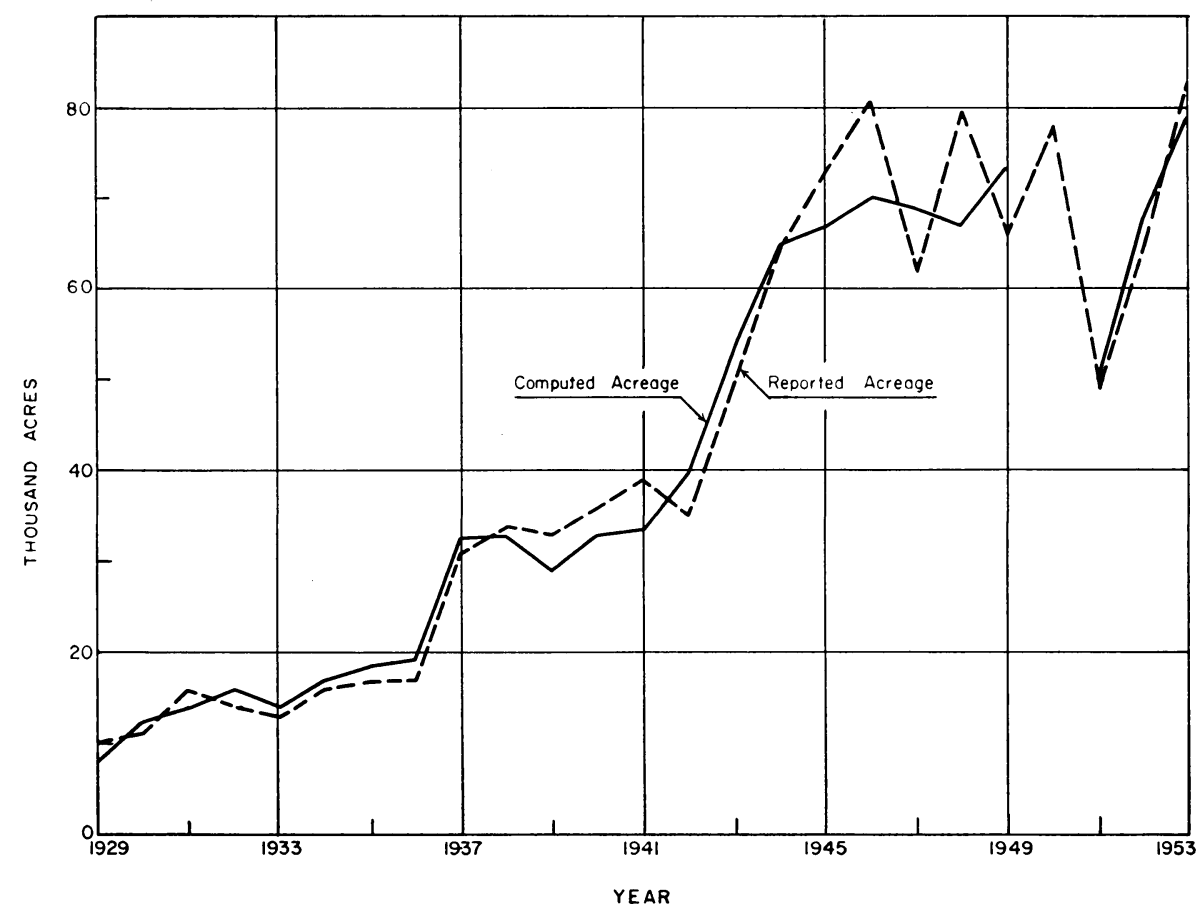

Fig. 2. Acreage of late spring potatoes in California, 1929-1953 (excluding 1950); a comparison of reported acreage with acreage estimates computed from the multiple regression equation (7).

$\log A_{P}=0.167690+0.236912 \log P_{P}+0.449828 \log P_{A}-0.229049 \log P_{c}+0.086045 t-$ $0.002041 t^{2}$

that the importance of the factors represented by the time variable (particularly yield) is decreasing. Future yield increases are expected to come from adoption of known practices, better disease and pest control, and new varieties, since further yield increases, due to fertilization practices and plant spacing, are believed to be very minor.

Equations 1, 3, 4, 5, and 6 are interpreted in the same manner as equation 2. Equation 7, being expressed in exponential form, is interpreted as follows: The coefficient of the price of late spring potatoes lagged one year indicates that, with effects of other variables remaining constant, a change of 10 per cent in late spring potato prices from the previous year was associated, on the average over the period studied, with a change in the same 
direction of 2.37 per cent in the acreage of late spring potatoes in California. The other coefficients in the equation can be similarly interpreted.

A graphic illustration of the "closeness of fit" obtained from equations 2 and 7 indicates that neither equation could be considered satisfactory in a period of relatively widely fluctuating acreage from year to year such as occurred in the period 1946 to 1950 (figures 1 and 2). The logarithmic formulation provided estimates more nearly in line with observed values during the first fifteen years of the period. In the period 1951 to 1953 there is little to choose between the two. Taking the entire period, it appears from the graphic presentation that equation 7 was slightly superior, but this is not considered to be conclusive.

\section{ELASTICITIES OF ACREAGE RESPONSE}

Absolute changes in the dependent variable often do not fully explain the nature of the relationships between independent and dependent variables. Percentage increases or decreases associated with percentage changes in the independent variables measured about an established point may reveal more information concerning these relationships. The elasticities of acreage response with respect to any of the independent variables, holding the effects of others constant, indicate these percentage changes.

When considering problems of acreage response in an irrigated agricultural area where several alternative enterprises are physically adapted to the area, the elasticity of response in any one enterprise to small changes in any other is a useful measure to indicate the relative importance of individual independent variables. Elasticity coefficients for five of the seven equations have been computed in order to obtain an indication of the importance of the three price and gross returns variables introduced into the equation (table 3).

TABLE 3

ESTIMATED ELASTICITY COEFFICIENTS COMPUTED FROM FIVE FORMULATIONS OF ACREAGE RESPONSE OF LATE SPRING POTATOES IN CALIFORNIA ${ }^{1}$

\begin{tabular}{|c|c|c|c|c|c|c|c|c|c|}
\hline \multirow{3}{*}{$\begin{array}{l}\text { Equation } \\
\text { numbers }\end{array}$} & \multicolumn{9}{|c|}{ Independent variables } \\
\hline & \multicolumn{3}{|c|}{ Potatoes } & \multicolumn{3}{|c|}{ Cotton } & \multicolumn{3}{|c|}{ Alfalfa } \\
\hline & $P_{P}$ & $P_{P}^{\prime}$ & $V_{P}$ & $P_{c}$ & $P_{c}^{\prime}$ & $V_{c}^{\prime}$ & $P_{A}$ & $P_{A}{ }^{\prime}$ & $V_{A}^{\prime}$ \\
\hline $1 \ldots \ldots$ & $\ldots \ldots$ & $\ldots \ldots$ & $0.277^{d}$ & $\ldots \ldots$ & $\ldots \ldots$ & $-0.616^{a}$ & $\ldots \ldots$ & $\ldots \ldots$ & $0.645^{b}$ \\
\hline $2 \ldots \ldots$ & $\ldots \ldots$ & $0.223^{c}$ & $\ldots \ldots$ & $\ldots \ldots$ & $\ldots \ldots$ & $-0.426^{a}$ & $\ldots \ldots$ & $\ldots \ldots$ & $0.912^{a}$ \\
\hline $3 \ldots$ & $\ldots \ldots$ & $0.101^{d}$ & $\ldots \ldots$ & $\ldots \ldots$ & $-0.177^{c}$ & & $\ldots \ldots$ & $0.544^{a}$ & $\ldots \ldots$ \\
\hline $5 \ldots \ldots \ldots$ & $0.376^{b}$ & $\ldots \ldots$ & $\ldots \ldots$ & $-0.137^{d}$ & & & $0.460^{b}$ & $\ldots \ldots$ & \\
\hline 7. & $0.237^{b}$ & $\ldots \ldots$ & $\ldots \ldots$ & $-0.229^{b}$ & $\ldots \ldots$ & $\ldots \ldots$ & $0.450^{a}$ & $\ldots \ldots$ & $\ldots$ \\
\hline
\end{tabular}

1 Letters in the body of the table refer to results of tests of significance for the estimates of coefficients of elasticity: $a=1 \%, \mathrm{~b}=5 \%, c=10 \%, d=25 \%$. The results are derived from testing the null hypothesis that $e=0$. A given coefficient of elasticity could be equal to zero only if the regression coefficient were equal to zero. Therefore, the results of the tests of significance applied to the estimates of the regression coefficients can serve as a test of the estimates of the coefficients of elasticity. For a discussion of testing elasticities derived from linear regression equations see Girshick (1942). 
The elasticity of acreage response for late spring potatoes $\left(A_{P}\right)$ with respect to any independent variable, say $P_{P}$, is defined as the relative (percentage) change in acreage associated with a corresponding small relative (percentage) change in potato price, when the effects of other variables remain constant. If the acreage changes at an increasing, constant, or decreasing rate with respect to any given independent variable, the elasticity of acreage response with respect to the given variable is said to be greater than unity, unity, or less than unity, respectively. Elasticities are customarily computed at the centroid, though elasticity values can be computed for any combination of assigned values for the independent variables. ${ }^{11}$

A computed coefficient of elasticity of acreage response with respect to one of the independent variables is less easily interpreted than estimates previously derived. The computed elasticity coefficient between potato price and acreage in equation 2 is 0.223 , indicating that, with the effect of independent variables remaining constant at their sample mean values, an increase (decrease) of 1 per cent in the farm price of late spring potatoes in California (averaged over the previous two years) was associated with an increase (decrease) of 0.223 per cent in the acreage of late spring potatoes in California. The same interpretation can be made for other elasticity coefficients computed from the five equations. It should be noted that the elasticity coefficients computed from equations $1,2,3$, and 5 would vary from year to year if computed from the observed values of the independent variables. By computing the elasticity coefficients with the independent variables measured at the centroid, an "average" elasticity is obtained, which may not represent any single observed relationship.

The absolute values of the coefficients of elasticity as computed from the various equations are all less than unity. Values for coefficients of the cotton and potato variables are essentially less than 0.5 . The conclusion can thus be drawn that acreage response is inelastic with respect to any of the independent variables considered explicitly. This suggests that statistical treatments of acreage response must take into account the effects of several alter-

${ }^{11}$ Given the general equation:

$\hat{Y}_{i}=a+b_{1} X_{1 i}+\cdots+b_{K} X_{K i}, \quad$ where $i=1 \cdots n$,

the elasticity coefficient of $\hat{Y}_{i}$ with respect to $X_{K}$ is defined as:

$$
\epsilon_{Y / X_{K}}=\frac{\partial \hat{Y}_{i}}{\partial X_{K i}} \cdot \frac{X_{K i}}{\hat{Y}_{i}}=b_{K} \frac{X_{K i}}{\hat{Y}_{i}},
$$

where $\hat{Y}_{i}$ is the computed value of the dependent variable in the $i$ th year and $X_{K i}$ is the value of the independent variable $X_{K}$ in the $i$ th year. When elasticity is computed at the centroid, all independent variables $\left(X_{1 i} \ldots X_{K i}\right)$ are valued at their mean in computing $\hat{Y}_{i}$. The elasticity coefficient is then:

$$
\epsilon_{Y / X_{K}}=b_{K} \frac{\bar{X}_{K}}{\bar{Y}},
$$

where $\bar{X}_{K}$ is the mean of $\bar{X}_{K i}$ and $\bar{Y}$ is the computed value for the dependent variable when the independent variables are set at their mean values.

In equation 7 , the estimates of the elasticities are the regression coefficients, and they remain constant for all observations of the independent variables. 
native enterprises as well as the price variables of the particular enterprise under consideration. Two variable acreage response studies will not suffice in a diversified agricultural area.

Some of the estimated elasticity and regression coefficients are not statistically significant at acceptable levels of significance. ${ }^{12}$ However, it cannot be concluded that the variables for which these estimates are computed are not relevant. It does suggest that more information is required in order to verify the importance of these variables which were introduced on the basis of a priori reasoning alone. The high intercorrelations between some of the variables can be cited as a cause for statistical nonsignificance in some of the estimates. ${ }^{13}$ Furthermore, the fact that a given variable which is logically included in the formulation is sometimes significant at an acceptable level of significance, depending on the particular formulation, is indicative of its importance.

The use of these results for direct prediction of the dependent variable for any given year is not considered to be their most important function, though acreage and supply response studies have been developed for this specific purpose historically. Some applications of these results to policy and program questions, however, are of particular interest to agricultural economists working with various farm organization and area production adjustments. Major emphasis will be given to these latter developments in the discussion of application of results.

\section{APPLICATIONS OF EMPIRICAL RESULTS}

The results of empirical studies of acreage response of this type can assist producer and industry groups, agricultural-policy and law makers, and persons charged with the responsibility for administering agricultural legislation. Statistically derived acreage response functions, when developed from sound data and interpreted in light of the empirical setting from which the basic relationships arise, can be of immeasurable assistance in quantifying the factors associated with aggregate acreage decisions arising from individual producer action. Two applications of the results of this analysis are considered. First, a brief discussion of the results as a predicting device indicates what types of predictions are possible, the errors associated with these predictions, and some of the statistical problems accompanying these estimates and errors. Second, the problems of achieving acreage and production goals by means of price manipulation in a diversified agricultural area are considered.

While the information presented to this point is not designed to develop a predicting mechanism, the relationships developed for the past may be relevant for the immediate future. For predicting purposes, best results are obtained if the equation having the smallest error of prediction is used, provided there is no a priori reason for selecting some other equation. This will provide the narrowest interval estimate for any given level of significance. However, there are circumstances where deviation from this criterion

\footnotetext{
${ }^{12}$ Levels not in excess of 5 per cent are conventionally considered acceptable. However, for some types of analysis, levels higher than 5 per cent might be considered acceptable.

${ }^{13} \mathrm{High}$ intercorrelation between the independent variables results in relatively large standard errors of the regression coefficients. See Fox and Cooney (1954) for a treatment of this problem.
} 
could result in the selection of a more accurate predicting mechanism. For example, if late spring potato acreage estimates were being developed in a year when cotton allotments were to be in effect, it might be advantageous to select an equation in which the regression coefficient for the cotton variable was of little relative importance and the regression coefficients of potato prices and alternative crop variables other than cotton were relatively important. Equation 4 would meet this specification.

If the empirical model developed is valid, it is possible to predict the acreage of late spring potatoes in California for any year and to make certain probability statements concerning this prediction. The procedure for deriving this prediction involves the substitution of observed values for the "explanatory" variables and algebraic solution for the dependent variable-acreage of late spring potatoes in California. This procedure is illustrated by computing a prediction of 1954 late spring potato acreage from equation 7 . The following values for the independent variables were substituted: in 1953 the seasonal average price received by California farmers for late spring potatoes $\left(P_{P}\right)$ was 85 cents per bushel, for cotton lint $\left(P_{c}\right) 31$ cents per pound, and for alfalfa hay (loose basis) $\left(P_{A}\right) \$ 17.50$ per ton, and the value of the time variable $(t)$ was 26 . The predicting equation with substituted values becomes:

$$
A_{P_{54}}=1.472(85)^{0.237}(31)^{-0.229}(17.5)^{0.450} 10^{0.086(26)-0.012(26)^{2}} .
$$

The solution of this equation gives a prediction of 50,097 acres of late spring potatoes in California in 1954.

Since all values inserted for the independent variables were lagged one year in this formulation, this estimate could have been made before the 1954 planting season. This, however, is not to suggest accuracy of the estimates arising from "complete information." A statistical error attached to this prediction must be considered. Assuming this error is normally distributed with zero mean and finite variance, a prediction interval can be established, based on the estimate of this variance. The 90 per cent interval for equation 7 for the year 1954 has a lower limit of 36,595 acres and an upper limit of 68,500 acres. ${ }^{14}$ If prediction intervals were computed from repeated sampling of the same population, they would embrace the true acreage 90 per cent of the time.

This interval is obviously of such width as to be of limited usefulness. The width of the confidence interval partly reflects the limited number of observations on which the estimate is based. This illustrates a weakness in the time series approach to supply response or to any other regression problem where the data available in time series are almost always limited in number of observations.

A further cause for the relatively wide confidence interval can be attributed to the use of the time variables and their role in prediction from this type of formulation. The confidence interval is narrowest when the explanatory variables are taken at their mean values. As these values depart from

${ }^{14}$ The acreage of late spring potatoes planted in California in 1954 is preliminarily reported as 56,000 acres, 47,300 acres of which are located north of the Tehachapi Mountains. 
their means, the interval broadens. ${ }^{15}$ Where a time or trend variable is included in the formulation, the value inserted for this variable is always an extreme observation. With the time variable raised to the second power, the impact on the width of the confidence interval is accentuated.

The usefulness of this type of prediction to individual producers is limited for several reasons. First, should any significant proportion of the total producers of any given commodity take the action which to them appears appropriate in light of the prediction (outlook), the actual realized acreage will probably differ significantly from the prediction. This assumes the prediction to be available in time for producers to alter their plans. Second, the predictions often do not become known to a very large number of producers (with the possible exception of members of various types of associations), and if the predictions are disseminated widely, many producers do not understand the full implication of the findings. This may in part offset the first objection to this type of information. Third, the limiting assumptions underlying this type of prediction are seldom known and even less appreciated by those persons who are interested in adjusting to this type of prediction. Producer groups are often prone to accept the "end result" of research of this type because of its source without attempting to gain full understanding of the capabilities and limitations of this type of analysis. As a result, the producer will attach more certainty to this prediction than it warrants. This action can then lead to further deviation between realized and predicted values.

Where nearly complete organization of producers of a given commodity has been accomplished, the results of this type of analysis can be valuable in establishing industry-wide production goals in an attempt to maintain the farm price above some specified level. The organization of California's late spring potato producers is not complete nor does the product they produce enjoy a completely independent market. However, in recent years the Kern County Potato Growers' Association has encouraged the membership and others in adjacent producing counties to restrict planted acreage. ${ }^{10}$ Observation of price-quantity relationships for late spring potatoes produced in this area has convinced growers that the demand function for their product in the relevant range is inelastic.

${ }^{15}$ Taking a two-variable model for simplicity, $Y_{i}=a+\beta X_{i}+u_{i}$, where the disturbance term $u_{i}$ is distributed with zero mean and variance of $\sigma^{\circ}$, the variance of the prediction error can be expressed as:

$$
\alpha_{Y i-\hat{Y}_{i}}^{2}=\sigma^{2}\left(1+\frac{1}{n}+\frac{(X \quad \bar{X})^{2}}{n S^{2}{ }^{2}}\right),
$$

where $\quad n=$ number of observations in the sample,

$S_{x^{2}}=$ sample variance of the observations of the independent variable,

$\bar{X}=$ sample mean of the observations of the independent variable,

$X^{*}=$ the value of the independent variable selected for prediction of the dependent variable.

The variance of the prediction error of the dependent variable is minimized for any given values of $n$ and $\sigma^{2}$ when $X^{*}=\vec{X}$. Increasing the number of independent variables in the analysis does not destroy this relationship. As the variance of the estimated value of the dependent variable increases, the prediction interval widens. Thus, for any given confidence coefficient the interval is narrowest around the mean.

${ }^{16}$ Approximately 72 per cent of the late spring potatoes in California are planted in Kern County, though in the past ten years the proportion has varied from 64 to 77 per cent. 
The second problem to which the results of this analysis have been applied is perhaps of more interest to economists. This problem involves the achievement of desired acreage (production) goals through manipulation of relative prices. Changes upward or downward in acreage from previous periods would be attainable. Practically, this approach would involve the establishment of a set of relative prices sufficiently far in advance to bring forth the given acreage at the time it is desired. During periods of war this is one major problem faced by administrators of governmental agencies in the United States charged with the responsibility of obtaining given absolute and relative quantities of various foods and fibers. But this application need not be confined to a wartime economy. A peacetime agricultural price program, which has been suggested as an alternative to the present pricesupport program, would require this type of empirical analysis on an area basis if it were to be feasible in practice. ${ }^{17}$

While this type of application possesses conceptual merit, the difficulties involved in practice must be made explicit. Structural changes in the industry, however slight, will greatly affect the efficiency of the model. Stability of the basic relationships becomes a prime necessity for this application of the technique to be practically feasible. In any policy application of this type, strict empirical findings would have to stand the scrutiny of experienced judgment before being placed in operation. The following is to be viewed and interpreted within these limitations.

A review of the results of this study clearly indicates that late spring potato acreage in California depends on prices and returns per acre for alternative enterprises as well as late spring potato prices. Thus, the simple price-output relationship (in this case price-acreage relationship) as depicted by the conventional theoretical supply function is not appropriate. When prices are established for late spring potatoes to bring forth a desired acreage, prices of alternatives must also be set which bear the appropriate relationship to the potato price (and production costs for potatoes and alternatives, technically speaking) if the potato acreage goal is to be met. Whether or not a particular price for potatoes is high or low in terms of acreage response depends on the prices of other crops which are alternatives to late spring potatoes in the farm organizations.

One solution to this problem is suggested by the results of this analysis. By setting the California late spring potato acreage goal at the level desired, the price required to achieve this goal can be expressed as a function of the prices of alfalfa and cotton, holding other variables in the equation, if present, at given values. This approach can be illustrated by computing the values required from any of the equations. Taking equation 7 , for example, the price relationships that will bring forth any given late spring potato acreage, say in 1954, can be derived as follows:

$$
A_{P_{54}}=11.2775 P_{P}^{0.237} P \bar{c}^{-0.229} P_{A}^{0.450},
$$

\footnotetext{
${ }^{17}$ Reference is made to the recommendations of Schultz and Johnson for a system of forward prices. One characteristic of these prices as explained by Schultz (1945) is that "the prices announced should be those prices which will achieve the desired output" (pages 264-265). A more complete treatment of a forward pricing system with minor reference to some of the statistical problems encountered in putting the system into operation is provided by Johnson (1947).
} 
from which $P_{P}$ (price of late spring potatoes in the period preceding) can be determined by.

$$
P_{P}=\left(\frac{A_{P_{54}} \cdot P_{c}^{0.229}}{11.2775 P_{A}^{0.450}}\right)^{1 / 0.237}
$$

By substituting a value for $A_{P_{54}}$ (the acreage goal for late spring potatoes in California) and establishing a price level for alfalfa, the combinations of cotton and potato prices that will result in the given potato acreage are determinable. If 60,000 acres of late spring potatoes are desired in 1954 and if an alfalfa price of $\$ 20$ per ton is established, then the relationship becomes:

$$
P_{P}=3.923 P_{c}^{0.966},
$$

from which a set of price combinations for late spring potatoes and cotton can be developed, resulting in 60,000 acres of late spring potatoes in 1954 . Similarly, the price of cotton can be established at a given level and a potato-alfalfa price relationship can be determined which will also result in 60,000 acres of late spring potatoes. This relationship, with $P_{c}=30$ cents per pound (price of cotton in the preceding period), would be:

$$
P_{P}=\frac{30,987}{P_{A}^{1.899}} \text {. }
$$

While this argument holds in the short run, the problem of acreage response with alfalfa-a perennial crop-would become important in the use of relative prices to direct acreages.

The values for $P_{P}, P_{A}$, and $P_{c}$, which have been interpreted as 1953 values to this point in the argument, could be announced prices (disregarding the methods of guaranteeing the announced prices) if the announcement were sufficiently in advance of the production season that individual producer decisions could be adjusted to the announced prices. This would involve making the prices known no later than the preceding fall. For a given late spring potato acreage in California in 1954, the prices would have to be announced in the fall of 1953 .

The numerical examples of these calculations have been reduced to twovariable combinations, the third fixed at a specified level, in order to permit graphic illustration. The case where cotton prices are fixed is first considered. It is to be noted that the iso-acreage lines thus derived are similar in concept to the isoquants of production theory. The coordinates, however, are not inputs but rather prices of the two alternatives being considered. Figure 3 illustrates the price relationships between potatoes and alfalfa, given the cotton price at 30 cents per pound of lint, which would bring forth given levels of potato acreage. Figure 4 depicts the same relationships but with the cotton price at the level of 20 cents per pound. With cotton at 30 cents per pound, prices of $\$ 20$ per ton for alfalfa and $\$ 1.05$ per bushel of late spring potatoes would be expected to bring forth 60,000 acres of late spring potatoes (figure 3 ). If the cotton lint price were reduced to 20 cents per pound, the same acreage could be obtained with $\$ 20$-per-ton alfalfa and a late spring potato price of about 71 cents per bushel (figure 4 ). 
The general contour of the iso-acreage functions is of interest in light of the complementary and competitive enterprise interrelationships existing. Given the cotton price, an increase in the acreage of late spring potatoes can be induced by either an increase in the price of potatoes or an increase in the price of alfalfa because of the complementarity of alfalfa and potatoes

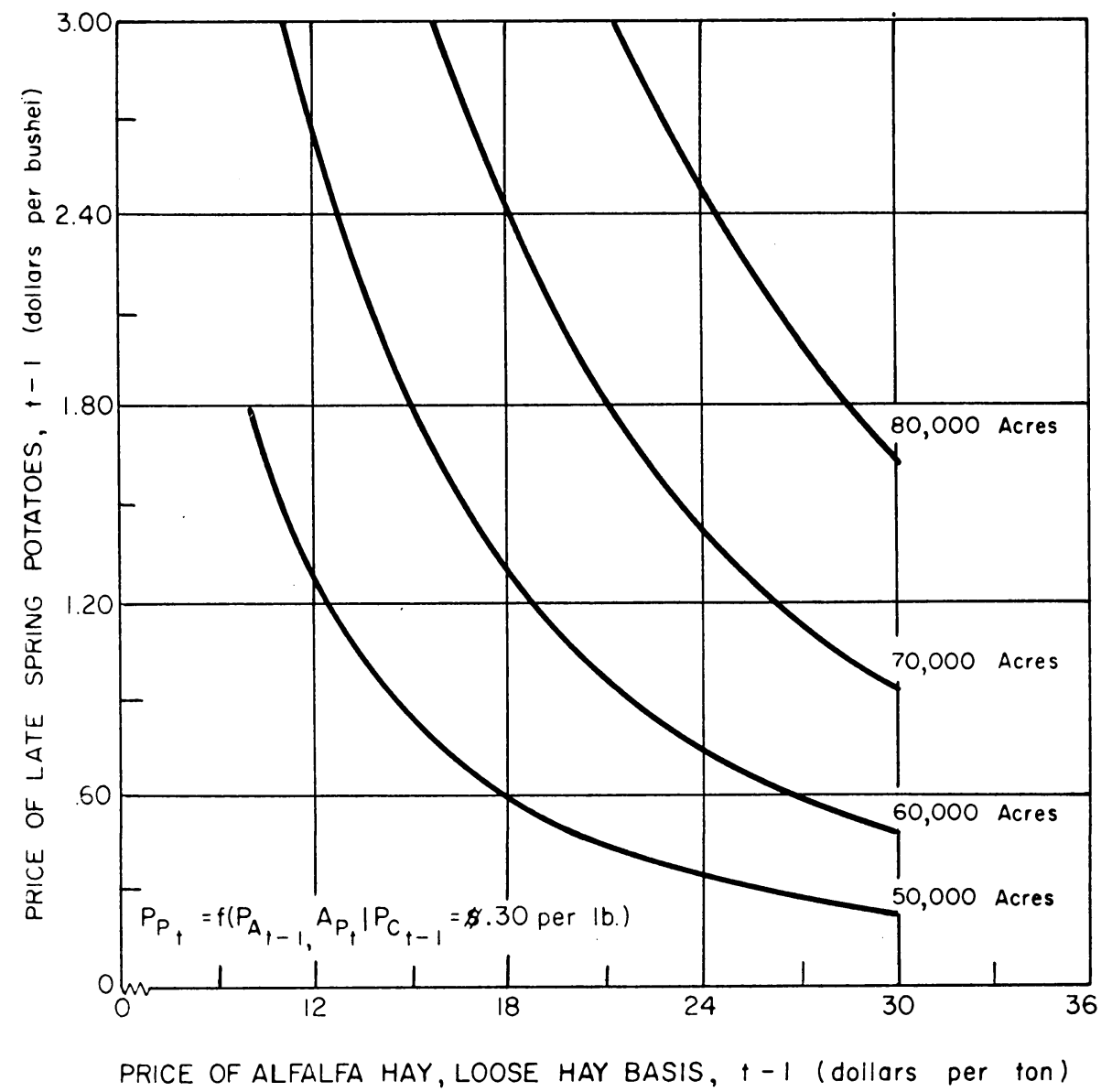

Fig. 3. Functional relationships of California late spring potato prices and alfalfa prices, given cotton lint price at 30 cents per pound, which are expected to result in specified acreages of late spring potatoes in the subsequent year. Source: table 4 (Appendix B).

and the competitiveness of cotton and alfalfa for the critical resource, water, as explained earlier. As the potato price reaches lower levels, greater increases in alfalfa prices would be required to bring forth the given potato acreage. However, small increases in the price of late spring potatoes, when initial prices are relatively low, will result in greater acreage increases than will small increases when the initial price is relatively high.

Turning now to the graphic illustration of the cases where alfalfa prices are held at given levels, a different relationship is readily apparent. A given acreage of late spring potatoes can be achieved for any given level of alfalfa 
prices with combinations of cotton and potato prices that bear nearly constant positive ratios to one anther. For example, if 60,000 acres of late spring potatoes in California is the goal and the alfalfa price is established at $\$ 20$ per ton, this can be achieved with 25-cent-per-pound cotton lint and

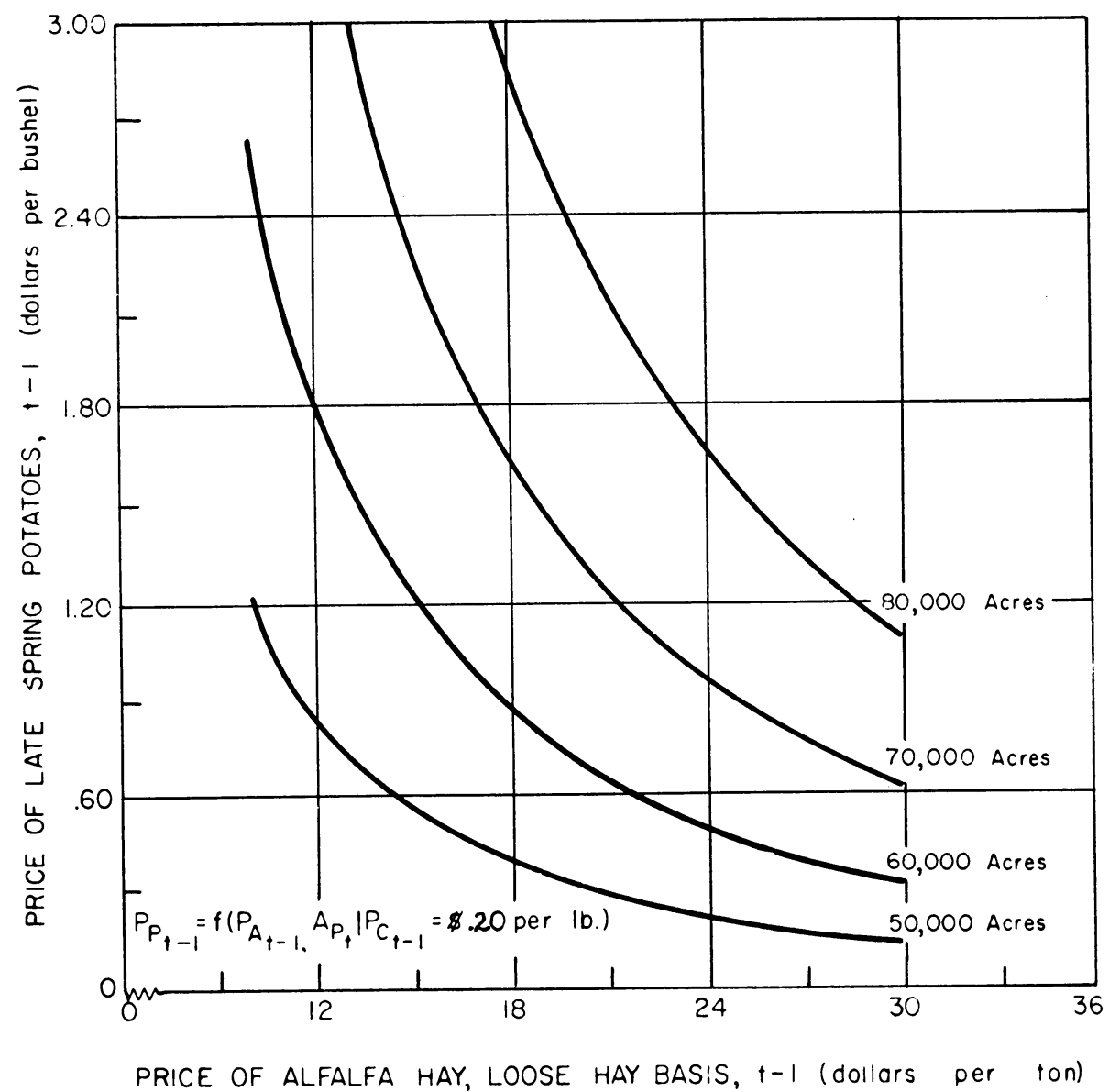

Fig. 4. Functional relationships of California late spring potato prices and alfalfa prices, given cotton lint price at 20 cents per pound, which are expected to result in specified acreages of late spring potatoes in the subsequent year. Source: table 5 (Appendix B).

88-cent-per-bushel late spring potatoes or with 30 -cent cotton and $\$ 1.05$ potatoes, a ratio of approximately 1 to 3.5 (figure 5$) \cdot{ }^{18}$ For 70,000 acres of late spring potatoes, a price ratio of approximately 1 to 6.8 would be required.

By increasing the alfalfa price, any given acreage of late spring potatoes can be achieved with a reduced price ratio of cotton to potatoes. For example,

${ }^{18}$ The ratios represent the ratio of cotton lint prices per pound to late spring potato prices per bushel. While these ratios are not in fact constant over the range of alternative prices required to bring forth any given acreage, they are very nearly constant since the exponent in the logarithmic function has the value of 0.966 ; a value of 1.0 would result in a constant ratio. 
60,000 acres would be expected when the expected cotton price was 30 cents per pound of lint and the late spring potato price 69 cents per bushel, a ratio of 1 to 2.3 (figure 6 ). Considering the relationships required to bring forth 80,000 acres of late spring potatoes, a ratio of 1 to almost 7.7 in the

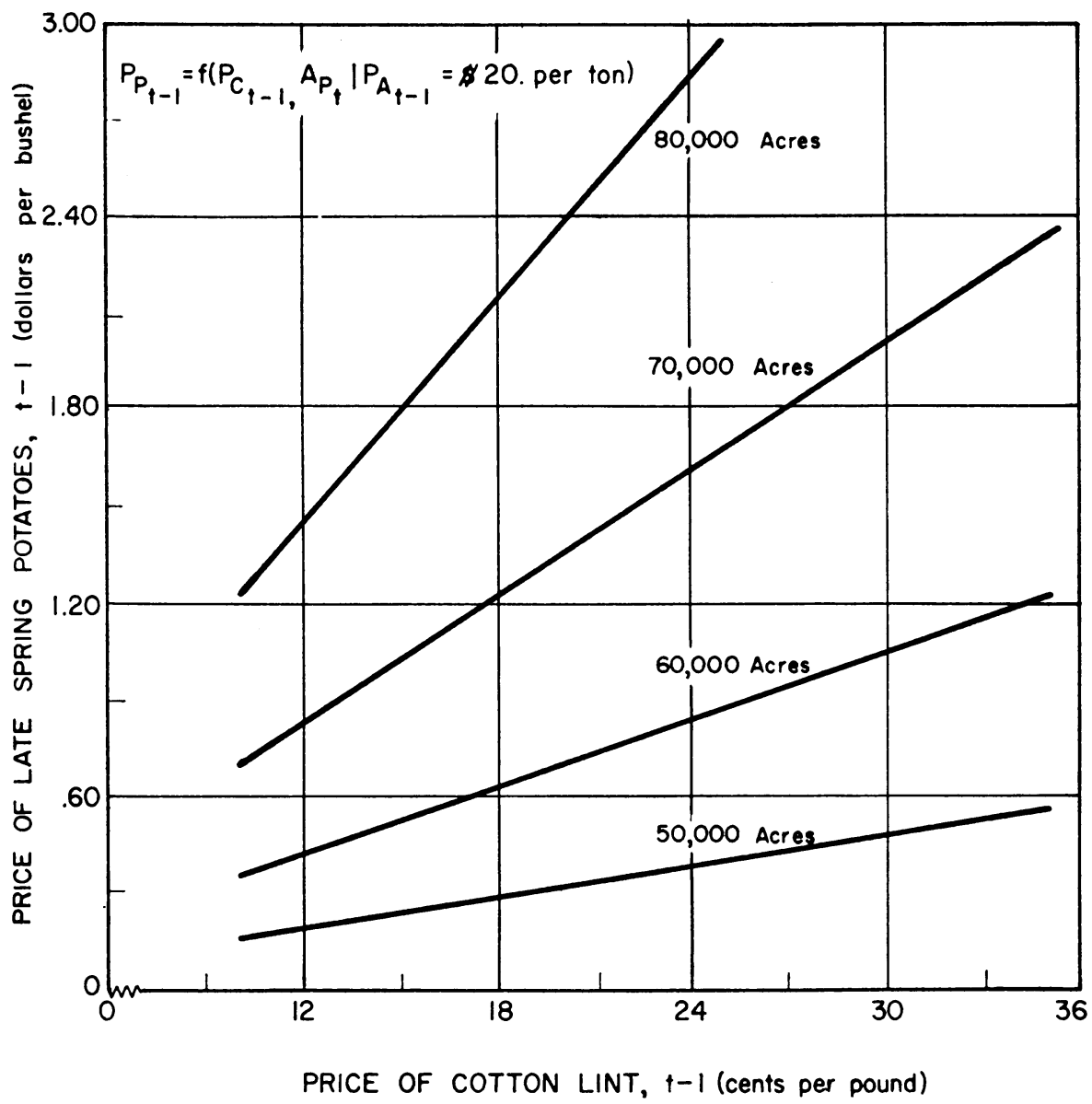

Fig. 5. Functional relationships of California late spring potato prices and cotton lint prices, given the price of alfalfa hay at $\$ 20$ per ton (loose basis), which are expected to result in specified acreages of late spring potatoes in the subsequent year. Source: table 6 (Appendix B).

price of cotton to that of late spring potatoes is needed. Considerable care must be taken in interpreting the graphs 5 and 6 , particularly as the higher cotton or potato price levels are reached. It would be logical to assume that it would be exceptionally difficult to achieve a large acreage of late spring potatoes when cotton prices were very high both absolutely and relative to potatoes. However, on most farms in the area to which this study is applicable, extreme cotton prices cannot bring forth much added acreage of cotton, since further expansion of cotton on the existing farms is limited by water availability. Since the cotton and potato enterprises are complementary in their use of this limited resource, very high cotton prices should 
not restrict potato acreage as long as potatoes are favorably priced with competitive alternatives. Recognizing this problem, the functional relationships depicted, if extended to the right, would logically be expected to become less steep.

Several weaknesses in this approach to the problem of production manipulation without acreage allotments must be recognized. A major problem with California late spring potatoes arises from the fact that the market

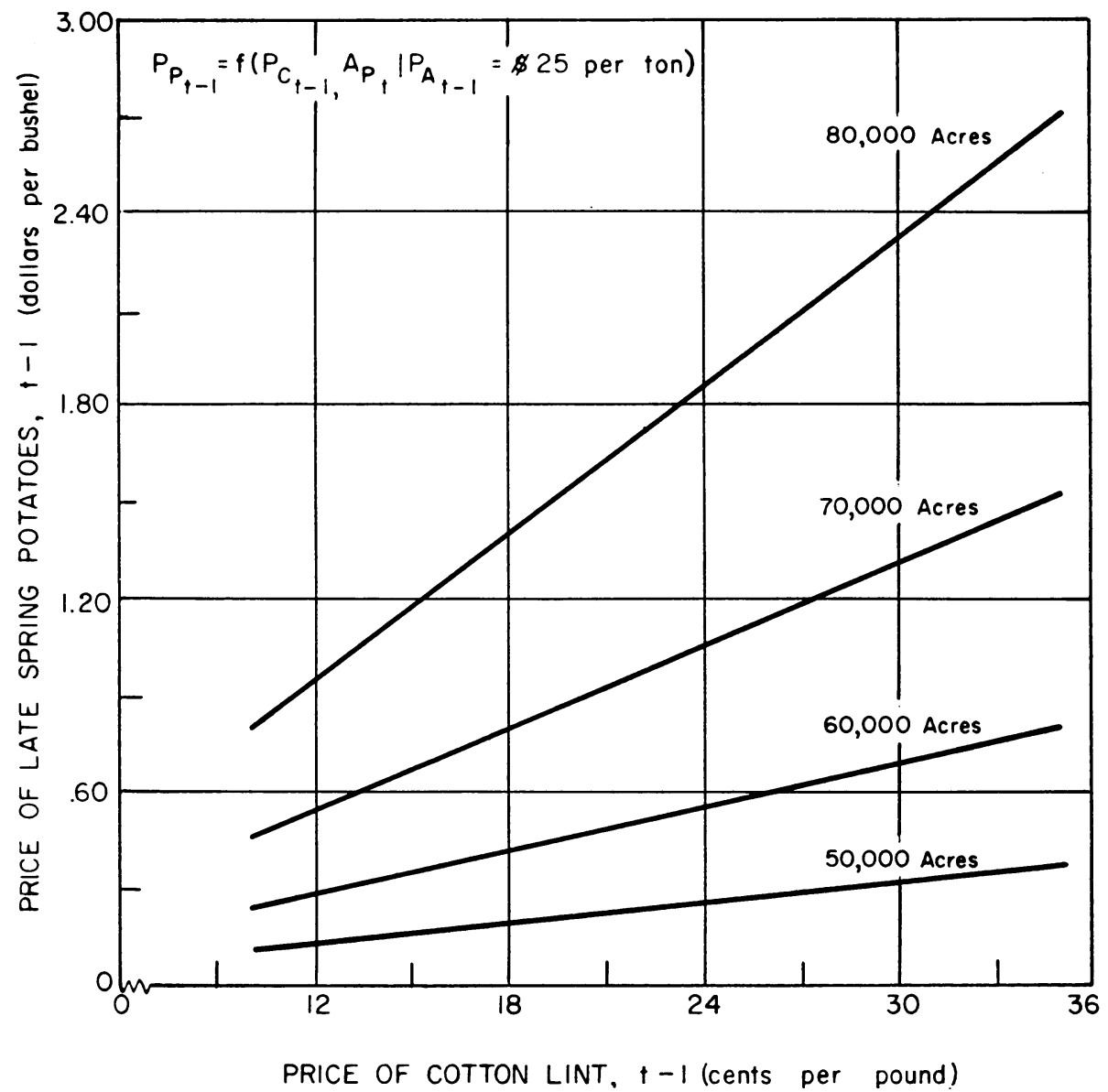

Fig. 6. Functional relationships of California late spring potato prices and cotton lint prices, given the price of alfalfa hay at $\$ 25$ per ton (loose basis), which are expected to result in specified acreages of late spring potatoes in the subsequent year. Source: table 7 (Appendix B).

is not an independent one. Increasing potato production in other areas of the United States in the same season and extended storage periods subject to manipulation based on price outlook tend to complicate and modify the practical application of the findings of this analysis. However, this does not destroy the usefulness of this approach as a guide to the administration of possible production and price programs.

If one or more of the alternative crops included in this analysis should 
go under a production-control program, the adjustments on individual farms might be such as to destroy the historical organization characteristics upon which the analysis rests. This would be, in essence, a structural change referred to earlier.

The implications of combinations of values for the independent variables outside the range of observed combinations, when these findings are applied to practical problems, must be recognized as well as specific values for independent variables which may not have been observed. Both types of extrapolation can be misleading. However, the problem of unobserved combinations is more serious in functions where the relationships are considered as joint rather than merely additive. In any event, care must be exercised in applying these findings and interpreting results of application to problems outside the scope, method, and data of the initial study.

\section{SUMMARY AND CONCLUSIONS}

1. The purpose of this study is to apply known statistical techniques to the problem of late spring potato acreage (supply) response in California.

2. Acreage of potatoes was substituted for supply in the computations. The rationale for this substitution was as follows: Supply is a product of acreage and yield. Yields are considered to be less sensitive to economic stimuli than acreage, year-to-year changes in yields in an irrigated area reflecting primarily changes in technology. An investigation of the net relationship between lagged prices and subsequent yield indicated that the regression coefficient of the price variable was not significantly different from zero at any acceptable level of significance. Acreage decisions are made prior to the planting period and these decisions are considered to have the greatest influence on total production.

3 . Those factors selected a priori as the pertinent independent variables affecting the acreage decision were: (1) expected per-acre returns obtained from alternatives-alfalfa and cotton (others are certainly influential but are of lesser importance), (2) expected returns from late spring potatoes, (3) total cultivated acreage in annual crops and alfalfa in Kern County (the leading county in acreage of late spring potatoes in California), and (4) time-trend variables. Expectation being unknown, lagged values were substituted for expected values on the grounds that farmers base their expectations largely on past experiences. Though net returns per acre. would be the logical values on which to compare alternatives, the absence of adequate historical cost data necessitated the substitution of gross returns and prices as approximations. Time variables were included to introduce the net effects of related factors, the effects of each being too small to consider independently.

4. The results of the regression analyses indicate that the late spring potato acreage in California was positively associated with lagged potato prices (returns), with lagged alfalfa prices (returns), and with total land available for annual crops and alfalfa. The acreage of late spring potatoes was negatively associated with lagged cotton prices (returns). The net relationship between the time and time-squared variables and late spring potato acreage was positive and negative respectively, suggesting the declining influence of the time factor through time over the period studied. These 
results were consistent with hypotheses of complementarity between potatoes and alfalfa with respect to the critical water resource and competitive relationships between potatoes and alfalfa on the one hand and cotton on the other hand for the same resource.

5. Elasticities of California late spring potato acreage with respect to individual alternatives indicate that acreage response is inelastic with respect to any single independent variable. This finding is in keeping with expected relationships in a diversified agricultural area.

6. Two specific applications of the findings of this study indicate the types of policy problems in which this type of analysis is helpful. The obvious application is in predicting late spring potato acreage for the forthcoming year. A second application suggested concerns the possibility of meeting given acreage goals for late spring potatoes in California through price manipulation as suggested in various agricultural programs turning on forward pricing systems.

\section{ACKNOWLEDGMENTS}

The authors gratefully acknowledge the assistance of the following persons who offered many helpful suggestions in formulating the problem and in preparing the final manuscript. Professors G. M. Kuznets and I. M. Lee were particularly helpful in the formative stage of this study. Professors E. C. Voorhies, G. L. Mehren, T. R. Hedges, J. Foytik, J. N. Boles, and J. H. Snyder reviewed the manuscript and suggested many improvements. Computations were carried on by members of the statistical pool of the Giannini Foundation under the direction of Mrs. Jane Zahn. Mrs. Emily Dougherty and Mrs. Margaret Rutishauser typed the many drafts.

\section{LITERATURE CITED}

BEAN, L. H.

1929. The farmers' response to price. Jour. Farm Econ. 11(3) : 368-385.

BLACK, J. D. (ed.)

1932. Research in farm management, scope, and method. Prepared under the direction of the Advisory Committee on Social and Economic Research in Agriculture. Social Science Research Council Bul. 13, p. 98-99.

Cox, R. W., and P. E. Quintus

1932. Minnesota farmers' response to price relationships in the production of selected crops. Jour. Farm Econ. 14 (4) : 697-700.

Elliott, F. F., and O. V. Wells

1932. Farmers' response to price in the production of flax. 33 p. U.S. Department of Agriculture, Bureau of Agricultural Economics. A preliminary report.

Ezekiel, Mordecai

1928. Statistical analysis and the "laws" of price. Quart. Jour. Econ. 42(2) : 199-227.

1938. The cobweb theorem. Quart. Jour. Econ. 52(2) : 225-280.

Fox, Karl A., and JAs. F. Cooney, JR.

1954. Effects of intercorrelation upon multiple correlation and regression measures. 28 p. U.S. Department of Agriculture, Agricultural Marketing Service. (Mimeo.)

GIRshick, M. A.

1942. The application of the theory of linear hypotheses to the coefficient of elasticity of demand. Amer. Statis. Assoc. Jour. 39(218) : 233-237.

Girshick, M. A., and Trygve HaAvercmo

1947. Statistical analysis of the demand for food: examples of simultaneous estimation of structural equations. Econometrica 15(2) : 79-110. 
Hart, B. I., and J. Von NeumanN

1942. Tabulation of the probabilities for the ratio of the mean square successive difference to the variance. Ann. Math. Stat. 13: 207-214.

HARTKEMEIER, H. P.

1932. The supply function for agricultural commodities. Missouri Univ. Studies 7(4): $1-79$.

Johnson, D. GaLe

1947. Forward prices for agriculture. xiii +259 p. Univ. of Chicago Press, Chicago, Illinois.

KLEIN, LAWRENCE R.

1953. A textbook of econometrics. 355 p. Row, Peterson and Co., Evanston, Illinois, and White Plains, New York.

Koopmans, TJalling C., and WM. C. Hood

1953. The estimation of simultaneous linear economic relationships. Cowles Commission: Studies in Econometric Method, Monograph 14: 112-199. John Wiley and Sons, Inc., New York, N.Y.

MCCorkle, Chester O., JR.

1953. Northern Kern County cotton-potato farms-costs, returns, and scale of operations. 65 p. California Agr. Exp. Sta. Giannini Foundation Rept. 143 (No. 2 of a series). (Mimeo.)

McCorkle, Chester O., Jr., and Trimble R. Hedges

1952. Northern Kern County cotton-potato farms-organization, inputs, and costs. 89 p. California Agr. Exp. Sta. Giannini Foundation Rept. 137 (No. 1 of a series). (Mimeo.)

Mighell, R. L., and R. H. ALLEN

1940. Supply schedules-"long-time" and "short-time." Jour. Farm Econ. 22(3): 554577.

MOORE, H. L.

1925. A moving equilibrium of demand and supply. Quart. Jour. Econ. 39(3) : 357-371. SCHULTZ, HeNry

1938. The theory and measurement of demand. xxxi 817 p. Univ. of Chicago Press, Chicago, Ill.

SCHULTZ, THEODORE W.

1945. Agriculture in an unstable economy. xix +299 p. McGraw-Hill Book Co., New York, N.Y.

Schultz, T. W., and O. H. BrowNLEe

1942. Two trials to determine expectations models applicable to agriculture. Quart. Jour. Econ. 56(3) : 487-496. 


\section{APPENDIX A}

Functional and graphic presentation of the net relationship between the dependent variables and each of the independent variables individually for equation 2, holding the influence of the other independent variables constant, is included to illustrate the form and nature of the net relationships. The net regression coefficients now carry the influence of all independent variables the effects of which have not been specifically eliminated. For example, in this study of acreage response, the net regression of California late spring potato prices on late spring potato acreage carries a portion of the influence of factors not explicitly introduced into the model as independent variables.

The net regression of $X_{1}$ on any variable $X_{2}$ indicates the functional relationship between the computed value for the dependent variable $\hat{X}_{1}$ and $X_{2}$ when the influence of the other variables is held constant at their mean values. Assuming $j$ independent variables and a linear relationship, this relationship can be expressed as follows:

$$
\hat{X}_{12.34 \cdots i}=\bar{X}_{1}+b_{2}\left(X_{2 i}-\bar{X}_{2}\right),
$$

where

$$
\begin{array}{ll}
\hat{X}_{12.34 \ldots j_{i}=} & \text { the computed value of the dependent variable in the } i \text { th year } \\
& \text { with } X_{3 \ldots j} \text { held constant at their mean values, } \\
\bar{X}_{1} & \text { the sample mean of the dependent variable, } \\
X_{2 i} & =\text { the } i \text { th observation on } X_{2}, \\
\bar{X}_{2} & =\text { the sample mean of } X_{2} .
\end{array}
$$

The residual values obtained from the observed and computed values are then plotted around the net regression line. An examination of the graphic presentations indicates that the function selected "fits" the observations and little improvement would be achieved by changing the form of the hypothetical functional relationships. 


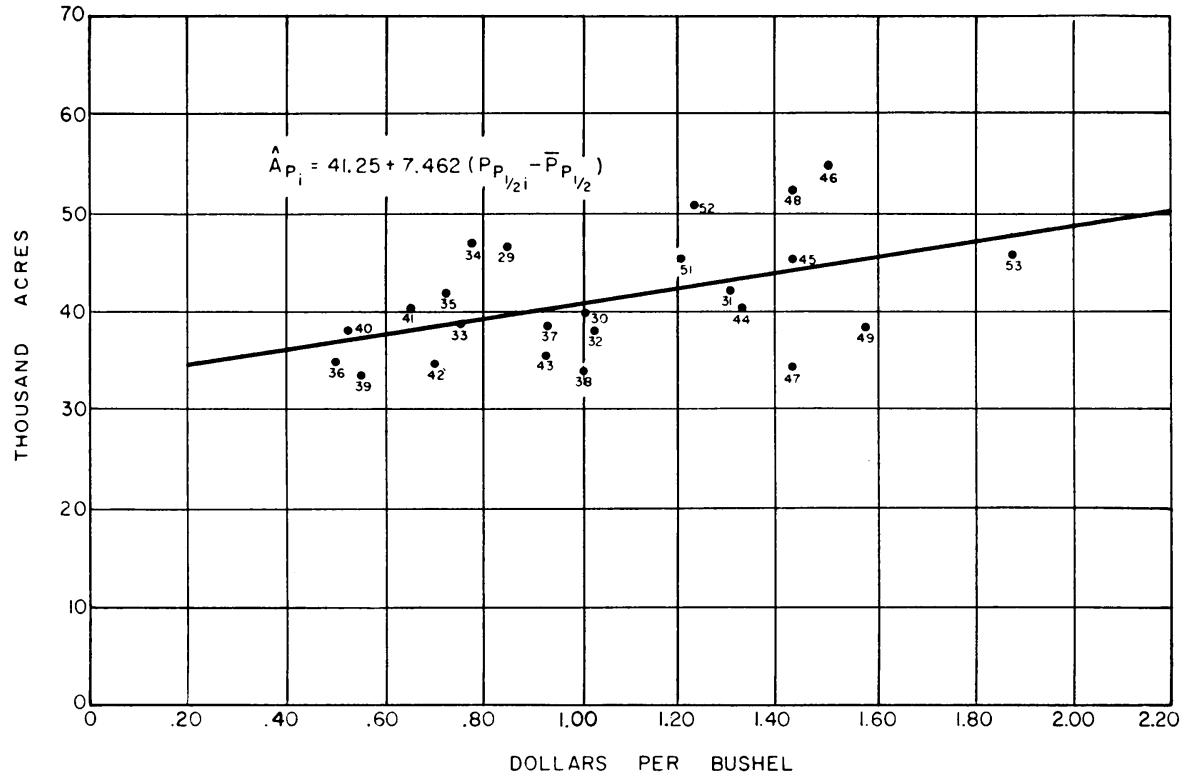

Fig. 7. Net regression of California late spring potato prices (average for two preceding years) on acreage of late spring potatoes in California.

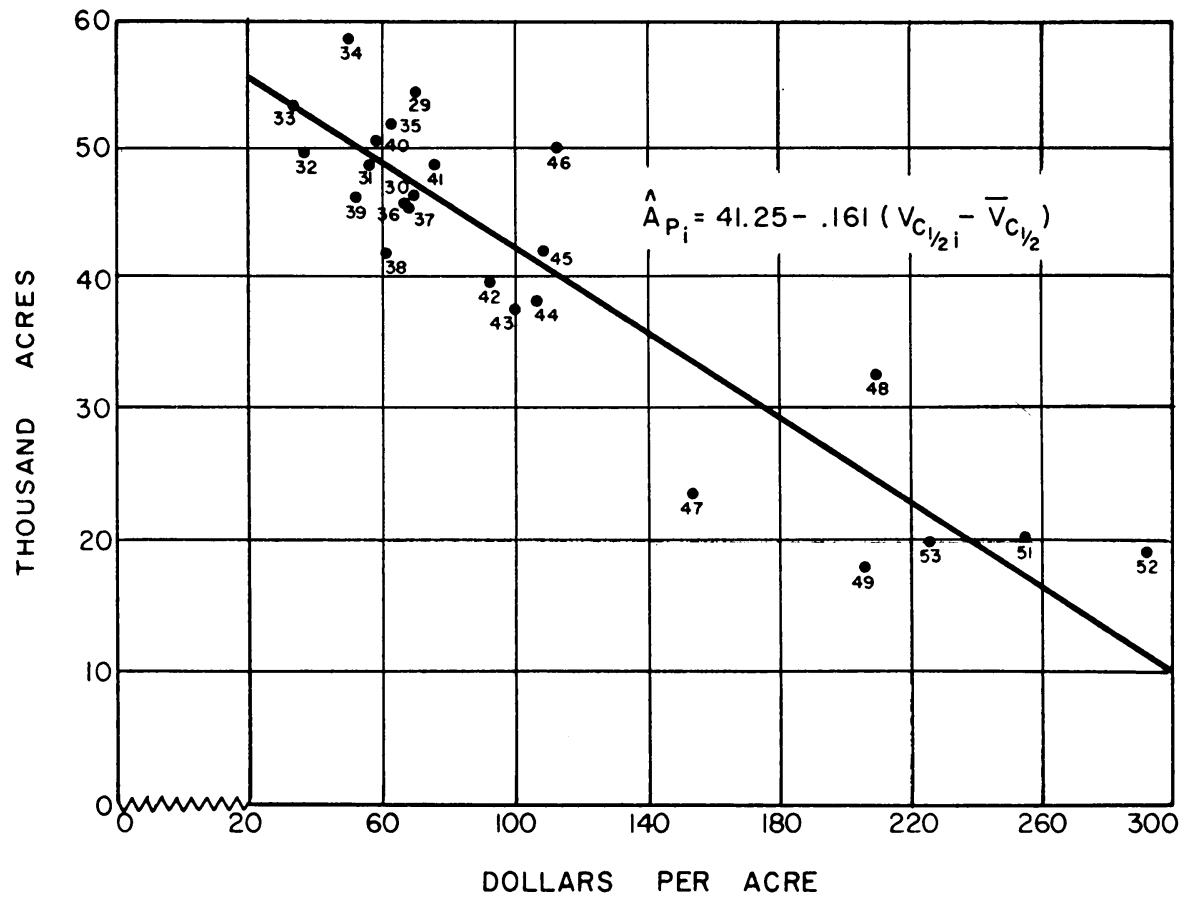

Fig. 8. Net regression of gross returns per acre for cotton in California (average of two preceding years) on acreage of late spring potatoes in California. 


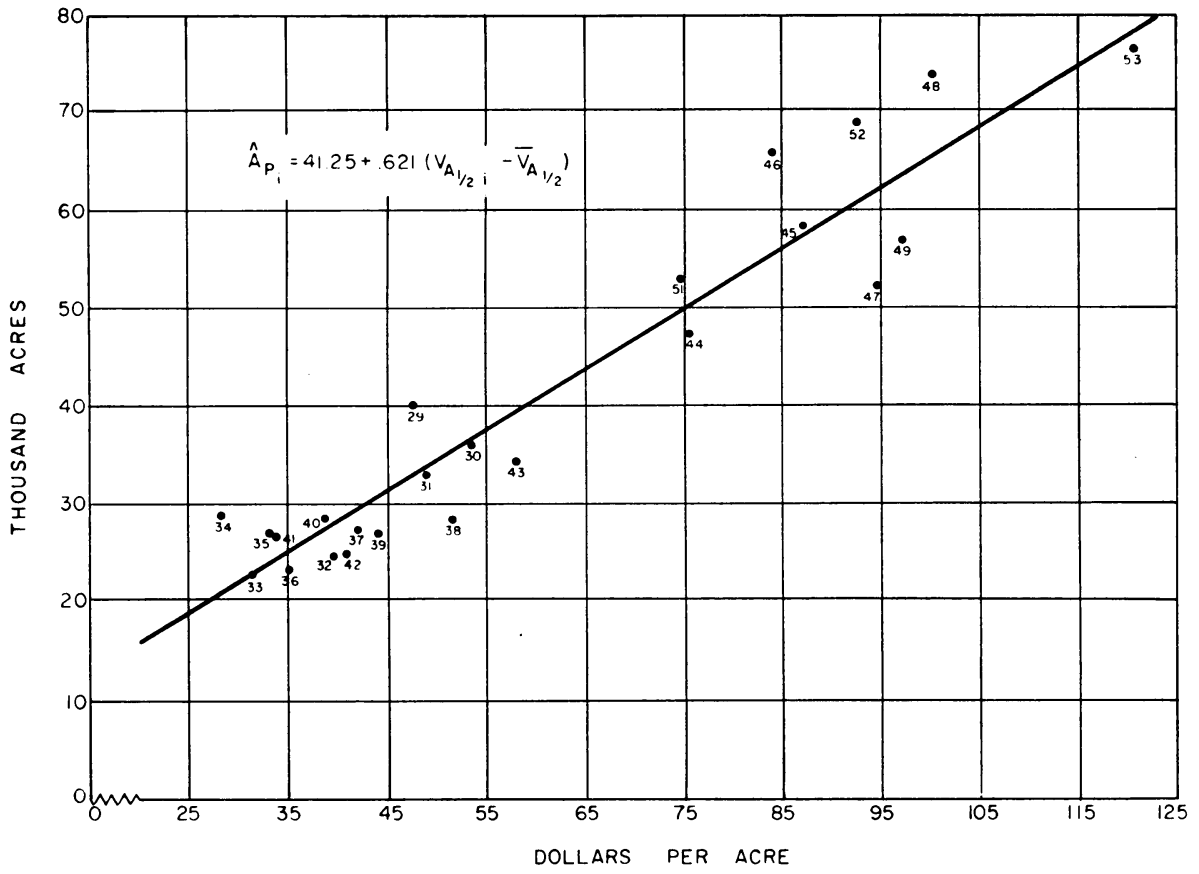

Fig. 9. Net regression of gross returns per acre for alfalfa in California (average of two preceding years) on acreage of late spring potatoes in California.

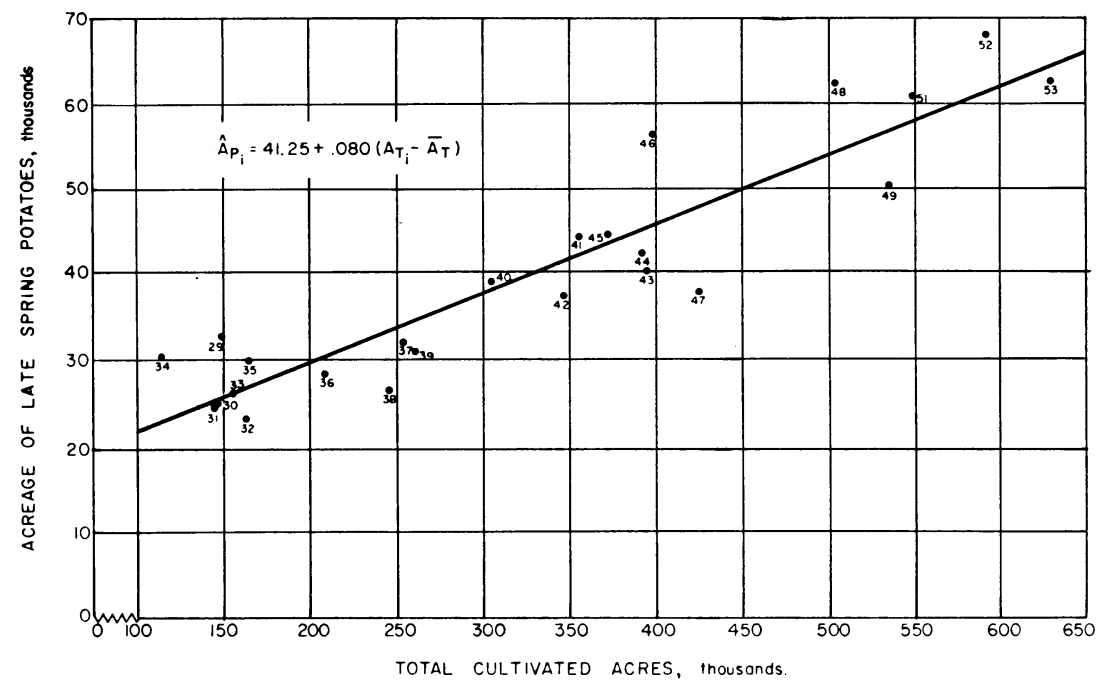

Fig. 10. Net regression of total cultivated acreage in Kern County planted to annual crops or alfalfa on acreage of late spring potatoes in California. 


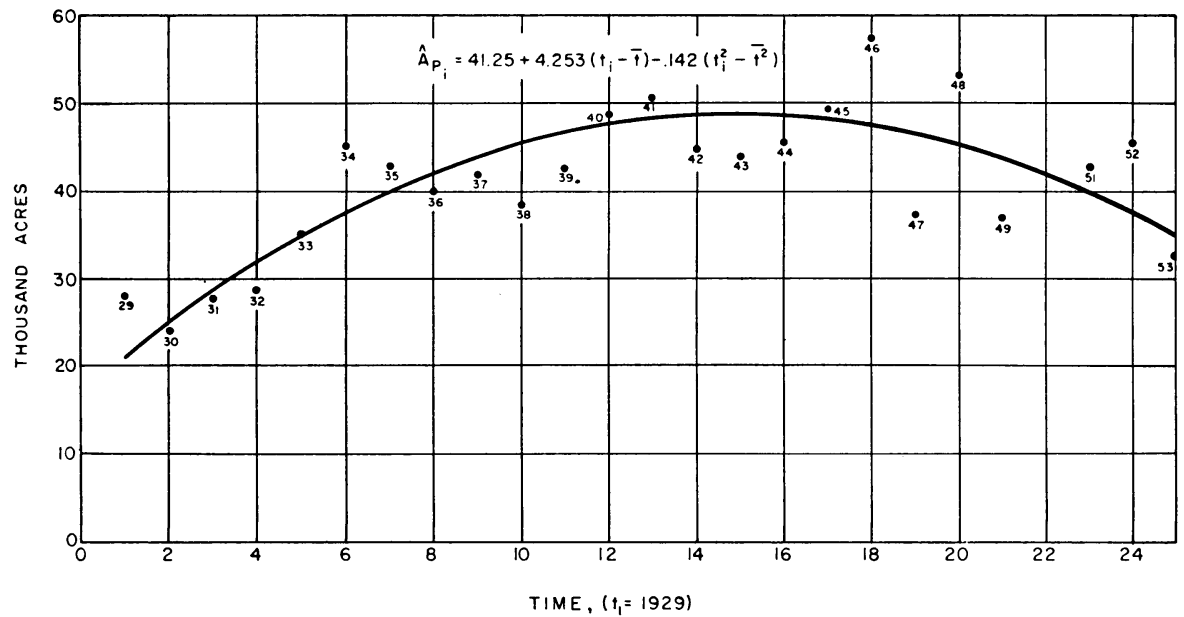

Fig. 11. Net regression of time variables on acreage of late spring potatoes in California. 


\section{APPENDIX B}

This appendix contains the data from which figures 3 through 6 were constructed. Essential computational values have also been shown to facilitate the calculation of combinations of prices not included in the tables or in the graphic presentations. It is mathematically possible to compute combinations of the dependent and independent variables which lie outside the observed range of observations. Such combinations have been avoided in this analysis on the grounds that inadequate information is available on the relative behavior of these prices in combination at extreme values. It is believed that the practical limits of each variable have been included in the tables below, given the basic data from which these values have been computed. The values $c^{*}$ and $d^{*}$ are merely computational values which have been included in the tables to facilitate the calculation of other values.

Computational Notes for:

Tables 4 and 5

$$
\begin{gathered}
A_{P_{54}}=11.275 P_{P_{t-1}}^{0.237} P_{{ }_{t-1}}^{-0.229} P_{A_{t-1}}^{0.450} . \\
P_{P_{t-1}}=\left(\frac{A_{P_{54}} P_{t-1}^{0.229}}{11.275}\right)^{1 / 0.273}\left(\frac{1}{P_{A_{t-1}^{0.450}}}\right)^{1 / 0.273}=c^{*} P_{A_{t-1}}^{-0.450 / 0.273} \\
\text { where } c^{*}=\left(\frac{A_{P_{54}} P_{t-1}^{0.229}}{11.275}\right)^{1 / 0.273}
\end{gathered}
$$

Tables 6 and 7

$$
\begin{aligned}
& A_{P_{54}}=11.275 P_{P_{t-1}}^{0.237} P_{{ }_{t-1}}^{-0.229} P_{A_{t-1}}^{0.450} . \\
& P_{P_{t-1}}=\left(\frac{A_{P_{5}}}{11.275}{\frac{5}{P_{t-1}^{0.450}}}^{0.0 \cdot 237}\left(P_{c_{t-1}}^{0.229}\right)^{1 / 0 \cdot 237}=d^{*} P_{c_{t-1}}^{0.229 / 0.237}\right. \\
& \text { where } d^{*}=\left(\frac{A_{P_{54}}}{11.275 P_{A-1}^{0.450}}\right)^{1 / 0.237} \text {. }
\end{aligned}
$$


TABLE 4

CALIFORNIA LATE SPRING POTATO AND ALFALFA PRICES, GIVEN COTTON LINT PRICE AT 30 CENTS PER POUND, WHICH ARE EXPECTED TO RESULT IN SPECIFIED ACREAGES OF LATE SPRING POTATOES IN THE SUBSEQUENT YEAR ${ }^{1}$

\begin{tabular}{|c|c|c|c|c|}
\hline Price of alfalfa $(t-1)$, dollars per ton & \multicolumn{4}{|c|}{$\begin{array}{c}\text { Price of late spring potatoes }(t-1) \text {, dollars per bushel, } \\
\text { at given levels of potato acreage }\end{array}$} \\
\hline $10 \ldots \ldots \ldots \ldots$ & 1.81 & 3.90 & $\ldots$ & $\ldots$ \\
\hline $20 \ldots$ & 0.48 & 1.05 & 2.00 & 3.52 \\
\hline 25 . & 0.32 & 0.68 & 1.31 & 2.30 \\
\hline 30. & 0.22 & 0.48 & 0.93 & 1.63 \\
\hline$c^{*} \ldots$ & 14,358 & 30,987 & 59,984 & 104,320 \\
\hline
\end{tabular}

${ }^{1}$ For purposes of illustration the year for which computations have been made is $1954(t=26)$.

TABLE 5

CALIFORNIA LATE SPRING POTATO AND ALFALFA PRICES, GIVEN COTTON LINT PRICE AT 20 CENTS PER POUND, WHICH ARE EXPECTED TO RESUL' IN SPECIFIED ACREAGES OF LATE SPRING POTATOES IN THE SUBSEQUENT YEAR ${ }^{1}$

\begin{tabular}{|c|c|c|c|c|}
\hline \multirow{2}{*}{ Price of alfalfa $(t-1)$, dollars per ton } & \multicolumn{4}{|c|}{$\begin{array}{c}\text { Price of late spring potatoes }(t-1) \text {, dollars per bushel, } \\
\text { at given levels of potato acreage }\end{array}$} \\
\hline & 50,000 acres & 60,000 acres & 70,000 acres & 80,000 acres \\
\hline $10 \ldots$ & 1.22 & 2.64 & $\ldots$ & $\ldots$ \\
\hline $20 \ldots$ & 0.33 & 0.71 & 1.35 & 2.38 \\
\hline 25. & 0.21 & 0.46 & 0.89 & 1.56 \\
\hline $30 \ldots$ & 0.15 & 0.33 & 0.63 & 1.10 \\
\hline$c^{*}$. & 9,704 & 20,943 & 40,135 & 70,501 \\
\hline
\end{tabular}

${ }^{1}$ For purposes of illustration the year for which computations have been made is $1954(t=26)$. 
TABLE 6

CALIFORNIA LATE SPRING POTATO AND COTTON LINT PRICES, GIVEN THE PRICE OF ALFALFA HAY AT \$20 PER TON (LOOSE BASIS), WHICH ARE EXPECTED TO RESULT IN SPECIFIED ACREAGES OF LATE SPRING POTATOES IN THE SUBSEQUENT YEAR ${ }^{1}$

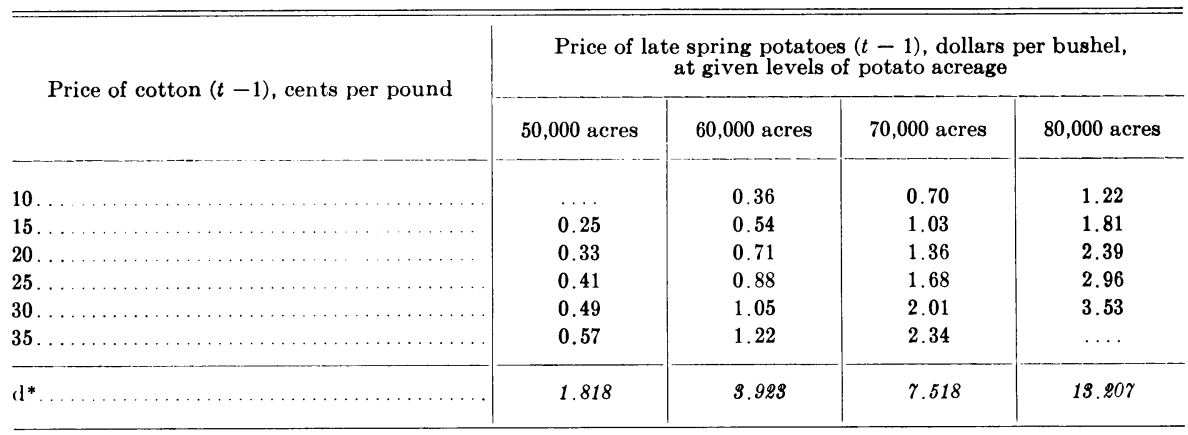

${ }^{1}$ For purposes of illustration the year for which computations have been made is $1954(t=26)$.

TABLE 7

CALIFORNIA LATE SPRING POTATO AND COTTON LINT PRICES, GIVEN THE PRICE OF ALFALFA HAY AT \$25 PER TON (LOOSE BASIS), WHICH ARE EXPECTED TO RESULT IN SPECIFIED ACREAGES OF LATE SPRING POTATOES IN THE SUBSEQUENT YEAR ${ }^{1}$

\begin{tabular}{|c|c|c|c|c|}
\hline \multirow{2}{*}{ Price of cotton $(t-1)$, cents per pound } & \multicolumn{4}{|c|}{$\begin{array}{l}\text { Price of late spring potatoes }(t-1) \text {, dollars per bushel, } \\
\text { at given levels of potato acreage }\end{array}$} \\
\hline & 50,000 acres & 60,000 acres & 70,000 acres & 80,000 acres \\
\hline $10 .$. & $\ldots$ & 0.24 & 0.46 & 0.80 \\
\hline 15. & $\ldots$ & 0.35 & 0.67 & 1.18 \\
\hline 20. & 0.22 & 0.46 & 0.89 & 1.56 \\
\hline $25 \ldots$ & 0.27 & 0.58 & 1.10 & 1.94 \\
\hline 30. & 0.32 & 0.69 & 1.31 & 2.31 \\
\hline $35 \ldots \ldots$ & 0.37 & 0.80 & 1.52 & 2.69 \\
\hline$d^{*} \ldots$ & 1.191 & 2.568 & 4.921 & 8.645 \\
\hline
\end{tabular}

${ }^{1}$ For purposes of illustration the year for which computations have been made is $1954(t=26)$. 


\section{APPENDIX C}

This appendix outlines the test for serial correlation which was employed to test whether or not one of the basic assumptions of the model introduced in this study was met. It will be recalled that independence in the error terms (disturbance terms) was assumed. When this assumption is not met, the formula for expressing the variance of the estimate is no longer applicable and tends to underestimate the true variance. Secondly, the $t$-distribution employed in testing the regression coefficients and in establishing confidence intervals is no longer valid. With these possibilities, the desirability of testing to determine whether or not the assumption of independence in the error terms is met becomes obvious.

The statistic employed to test for autocorrelation was the "ratio of the mean square successive difference to the variance" as worked out by Hart and Von Neumann (1942). With the disturbance term $U_{t}$, as used in the general model to represent the disturbance in any one of the equations at point $t$ in time, the statistic becomes:

$$
\frac{\delta^{2}}{S^{2}}=\frac{\sum_{t=2}^{T}\left(U_{t}-U_{t-1}\right)^{2}}{\sum_{t=1}^{T} U_{t}^{2}} \cdot \frac{T}{T-1} .
$$

However, $U_{t}$ is not an observed variate, but rather is estimated by $V_{t}=$ $A_{P_{t}}-\hat{A}_{P_{t}}$ where $A_{P_{t}}$ is the observed late spring potato acreage in year $t$ and $\hat{A}_{P_{t}}$ is the computed acreage for the same year. Admittedly, some bias is introduced by calculating the statistic using residuals from the regression equation rather than true residuals. The correction for this unavoidable bias is not as yet known.

The tables used in this test indicate the probability of getting a value for the statistic $\delta^{2} / S^{2}$ smaller than any particular value $K$, given the hypothesis of no autocorrelation where $K$ is a critical value varying with size of sample and level of significance.

Equations 1 and 7 were tested for autocorrelation, computation of the residuals appearing in table 8 . The critical values for $K$ for these two equations are $K_{1}=2.5$ and $K_{7}=2.2$. The highest value contained in the table for 25 observations is $K=1.5$ with probability 0.07398 . Symbolically:

$$
P\left(\frac{\delta^{2}}{S^{2}}<1.5 \mid H\right)=0.07398 .
$$

The probability increases with increasing values of $K$ and decreases as the size of the sample decreases. Therefore, since the hypothesis that no autocorrelation exists could be accepted with $K=1.5$ and $T=25$ at the 5 per cent level of significance, it could also be accepted at the same level with values of $K$ of 2.5 and 2.2 with a sample containing 24 observations. Thus, it can be concluded that no autocorrelation exists. 
TABLE 8

ACTUAL ACREAGE, COMPUTED ACREAGE AND RESIDUALS FOR EQUATIONS 1 AND 7

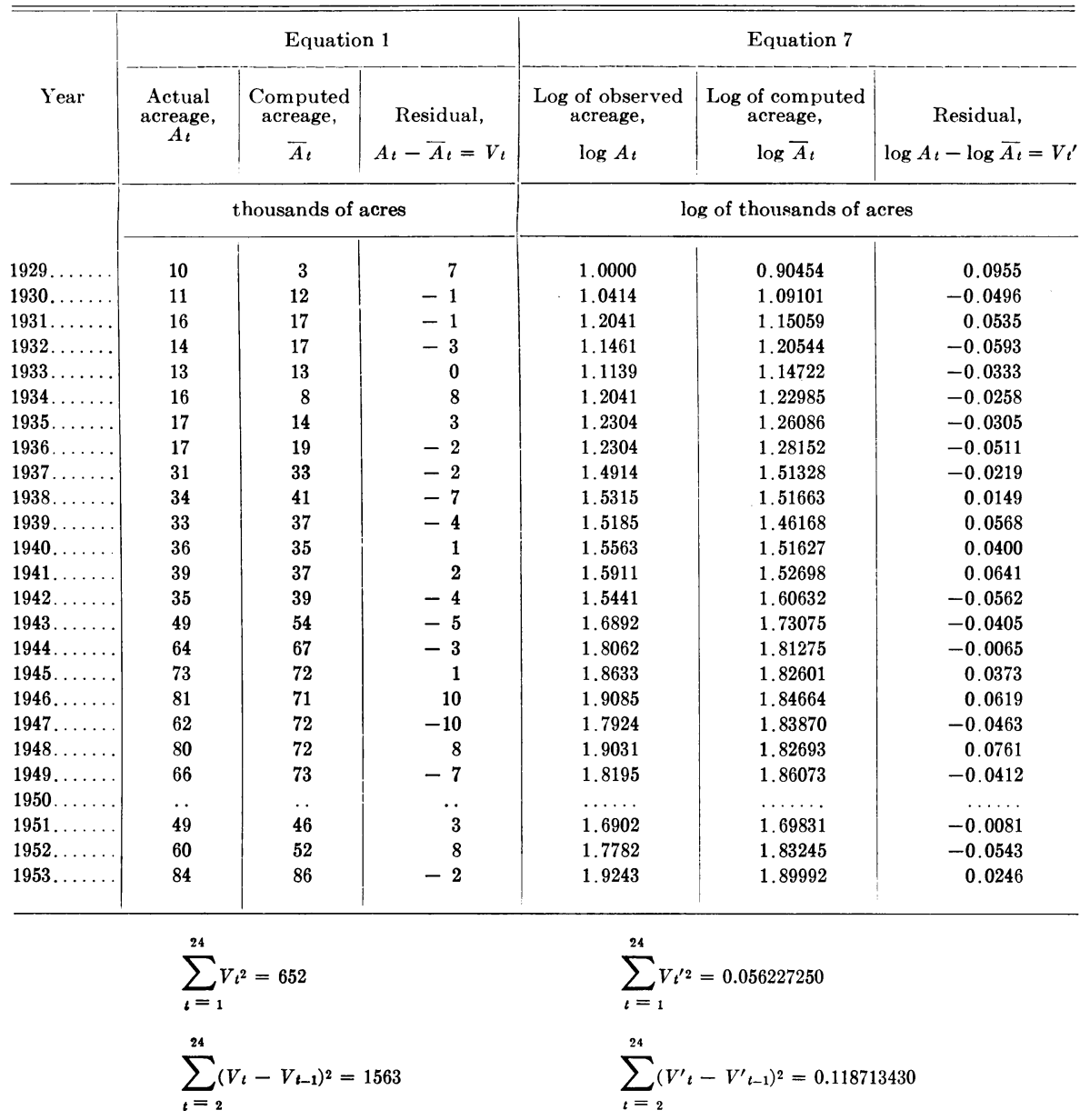




\section{APPENDIX D}

\section{The General Model}

In this section the general econometric model portraying the structural relationships in the late spring potato industry is presented as a basis for introducing the problem of supply response in its proper setting and for a framework in selecting pertinent, yet workable, variables for an analysis of supply response. ${ }^{19}$

The first equation of the general model is the shipment equation indicating that shipments $(Q)$ are some function of farm price $\left(P_{F}\right)$, harvest cost $(C)$ and production, that is, acreage $(A)$ and yield $(Y)$. Unless otherwise indicated, all variables refer to late spring potatoes. The relationship between farm price and harvest cost determines whether or not acreage is left unharvested in any one season. In recent years of fluctuating price and increased harvest costs, some acreage has not been harvested in years of relatively low prices. Thus, the symbolical formulation for the shipment equation is:

$$
Q=f\left(P_{F}, C, Y, A\right)+u_{1},
$$

$u_{1}$ being a disturbance term.

The demand relations at the retail level are expressed in such form that retail price $\left(P_{R}\right)$ is some function of shipments $(Q)$, personal disposable income $(I)$, competing shipments and supplies of potatoes $\left(Q_{c}\right)$, and time $(T)$. This can be expressed as:

$$
P_{R}=f\left(Q, I, Q_{c}, T\right)+u_{2} .
$$

The price at the farm level $\left(P_{F}\right)$ is a function of the retail price and the marketing costs $(M)$, or:

$$
P_{F}=f\left(P_{R}, M\right)+u_{3} .
$$

The yield $(Y)$ relationship is depicted as a function of the general level of potato yields $(\boldsymbol{G})$, expected price $(\boldsymbol{P} \boldsymbol{\epsilon})$, and the position on the particular production function $(L)$ selected by specific producers which in itself is partially determined by expected price. Thus:

$$
Y=f(G, P \epsilon, L)+u_{4} .
$$

Finally, the acreage $(A)$ is assumed to be a function of expected net income per acre from potatoes $\left(N_{P}\right)$ and from alternatives $\left(N_{A}\right)$ and of total acreage under cultivation in Kern County $\left(A_{K}\right)$ :

$$
A=f\left(N_{P}, N_{A}, A_{K}\right)+u_{\pi} \text {. }
$$

\footnotetext{
19 The particular econometric model portrayed is a shock model where errors arising from measurement are ignored, and the errors are viewed as arising from omitted variables. For a discussion and application of the shock model, see Girshick and Haavelmo (1947). Also see Koopmans and Hood (1953) for a discussion of problems in estimating parameters in shock models.
} 

The journal Hilgardia is published at irregular intervals, in volumes of about 600 pages. The number of issues per volume varies.

Subscriptions are not sold. The periodical is sent as published only to libraries, or to institutions in foreign countries having publications to offer in exchange.

You may obtain a single copy of any issue free, as long as the supply lasts; please request by volume and issue number from:
Agricultural Publications
Room 22, Giannini Hall
University of California
Berkeley 4, California

The limit to nonresidents of California is 10 separate issues on a single order. A list of the issues still available will be sent on request. 


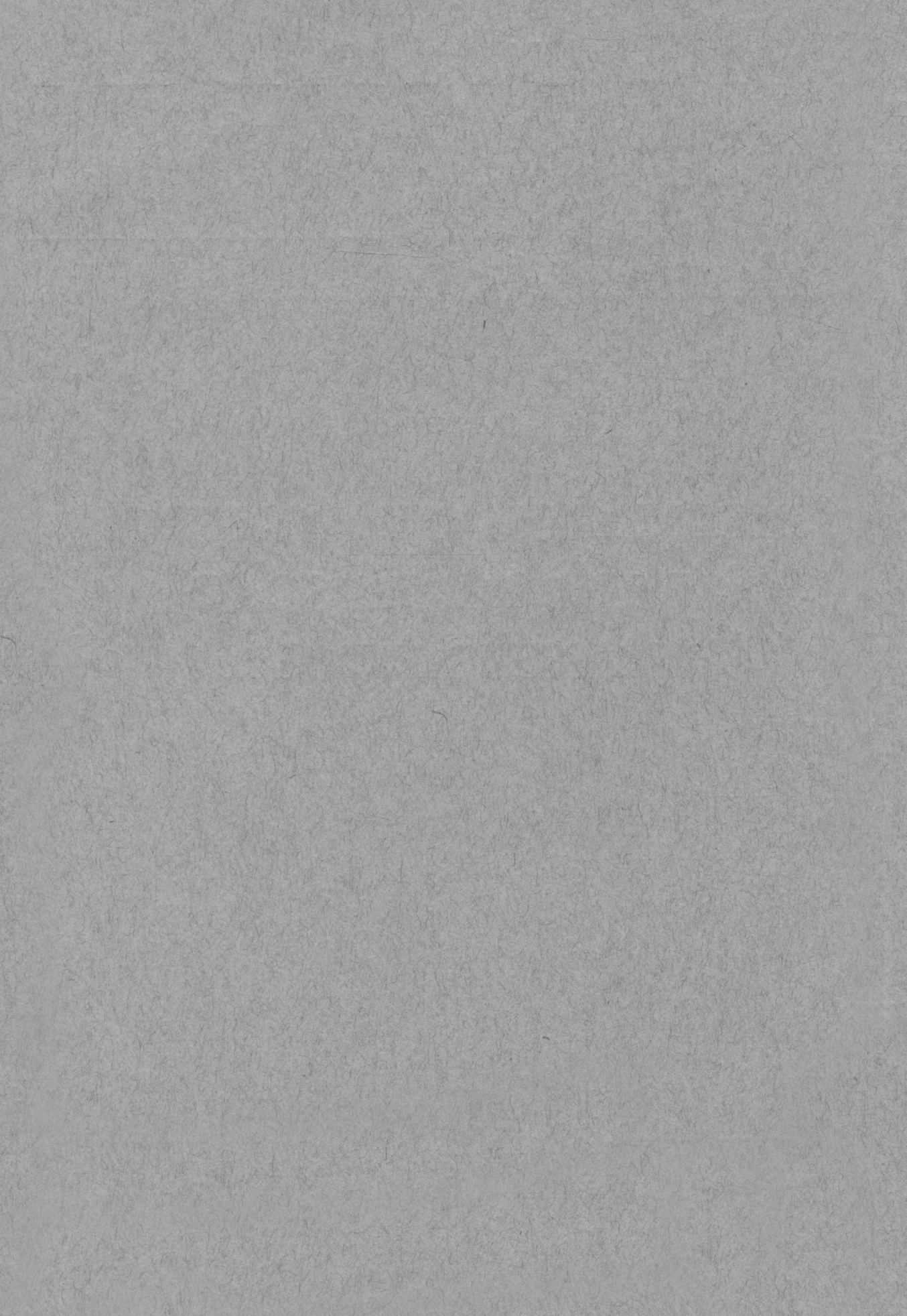

